AILEN'S DEFENCE OF THE EXTENDED OKDERING HYPOTHESIS:

A CRITICAL APPRAISAL

\author{
Thereza C. Botha
}

$1 \quad$ Introduction

This appraisal is directed at Allen's (1978) Extended Ordering Hypothes is (henceforth "EOH"), 1) which represents an "extension" of Siegel's (1974) Ordering Hypothesis. The latter hypothes is is formulated as follows by Siegel (1974:152):

\title{
ORDERING HYPOTHESIS
}
A. In English, Class I affixation precedes Class II affixation.
B. The cyclic stress assignment ruies follow Class I affixation and precede Class II affixation.

According to Siegel (1974:148), Class I affixes are introduced with a + boundary, whereas Class II affixes are introduced with a \#boundary. The association of different boundaries with the two classes of affixes captures the insight that Class I affixes are stress-determining, whereas Class II affixes are stress-neutral.

The EOH, as formulated by Allen (1978:83), reads as follows:

(2) $\mathrm{EOH}$

Compound formation follows all rules of affixation, and the assignment of external word-boundaries to lexical items is ordered after affixation rules but before compounding. ${ }^{2)}$ 
Allen (1978:7) argues for a level-ordered morphology. In such a morphology different types of word formation rules are ordered with respect to each other. Individual rules of the same type, however, are not ordered with respect to each other. A morphological theory which incorporates the hypotheses (1) and (2) expresses, among other things, the following two ordering claims:

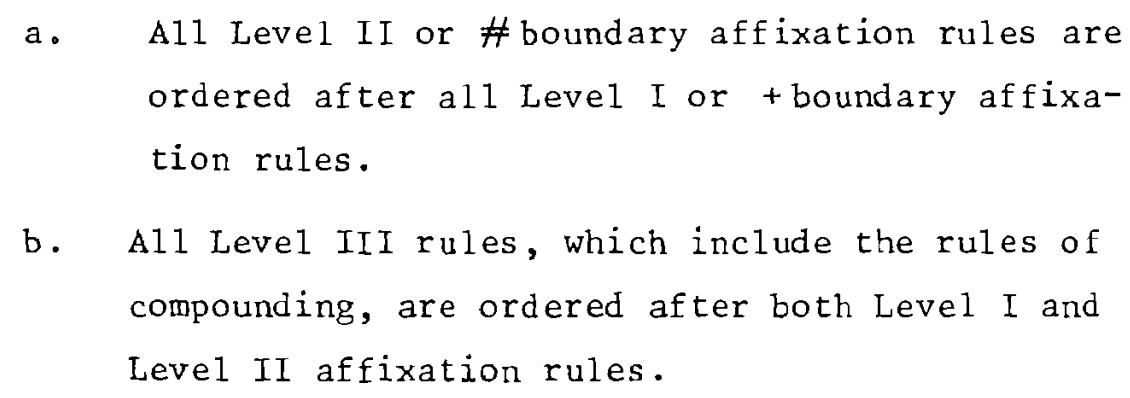

On the basis of (3), it is predicted that

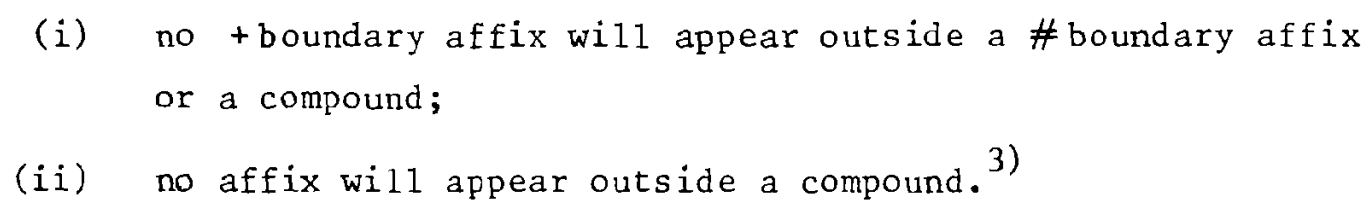

The primary aim of this paper is to determine the correctness of the ordering claim expressed by the $\mathrm{EOH}$, i.e. the correctness of the claim that no affixes may appear outside compounds. Allen (1978:232ff.) discusses various morphologically complex words of English in which, apparently, affixes appear outside compounds. The existence of such words poses a serious challenge to the EOH. However, she employs a number of strategies to protect the EOH from refutation by this apparent counterevidence. Her strategies for protecting the EOH will be analyzed critically.

Any attempt at empirical validation of a hypothesis such as the EOH must take account of the status which the hypothesis is supposed to have. In this regard the following question arises: 
(4) Did Allen intend the EOH to be a language-specific principle of English, or did she intend it to be a languageindependent principle?

Allen does not explicitly characterize the status of her morphological theory as either language-specific or language-independent. She (1978:1) merely states that the aim of her thesis is

"to determine the nature of the principles of word formation, and to investigate their interaction with other grammatical phenomena".

Furthermore, she does not explicitly restrict the scope of her study to the morphology of English in particular. She repeatedly refers to "(the) morphology". Consider, for example, remarks such as the following:

"The generative capacity of the morphology is decreased by
including the Strong Boundary Condition and the Extended
Ordering hypothesis as part of the theoretical machinery. "4) [Abstract]

"... there are three ievels in the morphology at which rules of word formation operate."

[p. 186]

"The Extended Ordering Hypothesis is a general ordering principle of morphology which drastically limits the number of possible combinations of prefixes and suffixes."

$$
\text { [p. 196] }
$$

"The theory of morphology for which I have argued ..."

$$
[p \cdot 214]
$$

There appears to be no reason to believe that Allen did not intend her general theoretical claims to have the status of language-independent principles. Matters are complicated, however, by the fact that Allen 
(1978:6) accepts Siegel's (1974) Ordering Hypothesis which is explicitly formulated for English only. Thus consider the following remark by Siegel (1974:152): "In English, Class I affixation precedes Class II affixa-
tion." 5 )

Although Allen makes no explicit statement to this effect, her acceptance of Siegel's Ordering Hypothesis could be taken to indicate that she intended the EOH to be a principle of English morphology alone.

The ambiguity in the status of the EOH entails that the claim that affixes may not appear outside compounds has to be tested both as a language-specific claim and as a claim about language in general. This paper is concerned with the question whether the EOH is correct as a language-specific principle. In the thesis (T.C. Botha 1982) on which this paper is based, the status of the EOH as a languageindependent principle is considered as well.

The remainder of this paper is organized as follows. In $\S_{2}$, the status of the EOH within the more general framework of Allen's theory of Overgenerating Morphology will be considered in some detail. The predictions of the EOH are presented in $\$ 3 . \quad \$ 4$ considers some putative counterexamples to the $\mathrm{EOH}$, as well as Allen's attempts at defusing the threat which these examples pose to the EOH. Finally, in $\$ 5$, I shall briefly look at other 1 inguists' views on the question of whether compounds can form the basis of affixation in English. The main findings of the paper are sumarized in $\$ 6$.

\section{The EOH within an Overgenerating Morphology}

Before the predictions of the $\mathrm{EOH}$ are considered, it is necessary to consider the nature of the relationship between Allen's (1978:189) theory of Overgenerating Morphology and her EOH. 
According to Allen (1978:189), al.1 word formation rules, including the compound formation ruies, apply to bases which are either (i) underived or (ii) potential well-formed outputs of word formation rules. Whether these potential words are also occurring words is not relevant at all. Allen thus regards ruies of word formation as overgenerating rules. According to her ( $1978: 195)$,

\footnotetext{
"Over-generating word-formation rules apply whenever the structural conditions of their application are met, and can be blocked only by general, independent ly motivated principles."
}
Allen (1978:189) uses the term Overgenerating Norphology to refer to this "model of the workings of morphological rules", as she phrases it. ${ }^{6)}$

Because Allen (1978:185) assumes an Overgenerating Morphology, she has to account for the fact that the word formation rules generate an infinite set of possible, well-formed words, only some of which are actual or occurring words in the Ianguage. In order to do this, she distinguishes between the Conditional Lexicon and the Permanent Lexicon. According to her $(1978: 189)$,

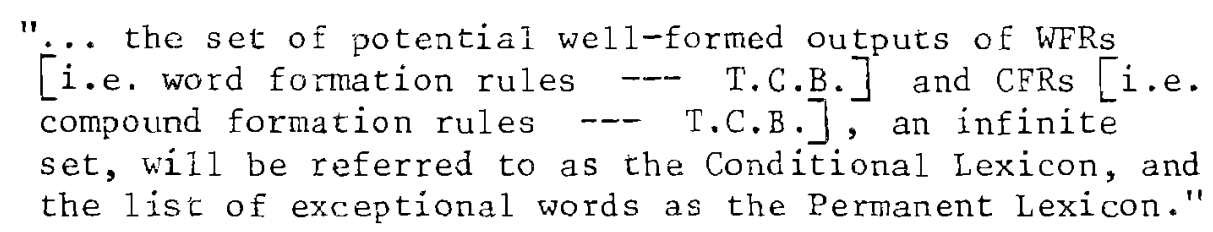

Allen (1978:196) regards the $\mathrm{EOH}$ as one of a set of general, independently motivated principles of morphology which restrict the ways in which word formation rules may interact. ${ }^{2}$ She $(1978: 196)$ formulates this view as follows:

"The Extended Ordering Hypothesis is a general ordering principle of morphology which drastically limits the number of possible combinations of prefixes and suffixes." 


\section{T.C. Botha 54}

According to Allen (1978:212), some interaction between an Overgenerating Morphology and the $\mathrm{EOH}$ is inevitable, since they are both principles of morphology which govern the application of word formation rules. Furthermore, she (1978:212) rejects the claim that the EOH can be maintained only in conjunction with an Overgenerating Morphology in certain cases. As Allen (1978:212) points out, both hypotheses are motivated on the basis of independent sets of data. For example, the fact that there are wel1-formed words in -ing and -ed which form the bases of other word formation rules, but which do not occur as independent words, provides evidence for postulating an Overgenerating Morphology. These facts, however, have nothing to do with the EOH. On the other hand, the fact that word-boundary affixes do not appear outside compounds, constitutes crucial evidence for the $\mathrm{EOH}$, but is independent of an Overgenerating Morphology.

Allen (1978:212-213) illustrates the nature of the interaction between an Overgenerating Morphology and the $\mathrm{EOH}$ with reference to the forms hunch-backed, pale-faced and dim-witted. According to her, the bracketings in (5)(a) violate the EOH, since a Level II suffix, \#ed, is bracketed outside a compound, which is formed at Level III. ${ }^{8)}$ By contrast, the bracketings in (5)(b) do not violate the EOH in any way. However, the bracketings in (5) (b) can only be assigned within an Overgenerating Morphology. The forms [backed], [faced] and [witted] are not "independently occurring words" in English.

(a) $\begin{aligned} & {[\text { hunch-back] ed }} \\ & {[\text { pare-face] ed }} \\ & {[\text { dim-wit] ed }} \\ \text { (b) } \quad & {[\text { hunch }][\text { backed] }} \\ & {[\text { pale }] \text { [faced }] } \\ & {[\text { dim }][\text { witted] }}\end{aligned}$

According to Allen (1978:213), there is ample evidence from the semantics and stress patterns of forms such as these in favour of a bracketing as in (5)(b). She (1978:213) thus concludes that 
"The fact that these bracketed forns [i.e. the forms bracketed as in (5) (b) above -- r.C.B.] are also consistent with the Extended Ordering Hypothes is can only be construed as a positive result." g)

We can now return to Allen's (1978:186) claim that all Level III rules must be ordered after all Level I and Level II affixation rules. Recail that Alien (1978:186) regards compounding as a Level III process. In other words, her clairn that all Level III rules must be ordered after al1 Level I and Level II rules amounts to the claim that no affixes can appear outside compounds. It is the correctness of this claim which I propose to challenge in this study.

Allen's distinction between affixation as Level I and II processes and compounding as a Level III process, is based on the assumption that the internal boundaries of forms derived by means of these processes differ. She (1978:125) presents two sources of evidence in support of this claim: (i) phonological evidence and (ii) morphological evidence.

(i) Phonological evidence

Allen (1978:121ff.) observes that there are a number of phonological distinctions which must be made at the internal boundary of compounds, i.e. [WORD] [WORD] forms, and words formed by means of \#boundary suffixation, i.e. [WORD] [\#SUF] forms. In order to account for these distinctions, she posits a distinction between two levels of word formation, viz. Level II for derivation and Level III for compounds. The phonological distinctions are the foliowing:

\section{a. the tense/i/ - /I/ alternation}

There is an alternation between the tense final / i/ in free-standing words and the lax /I/ in corresponding derivatives, formed by means of \#boundary suffixation. Compare, for example, the following forms:

$\begin{array}{lc}\text { Underived word } & \text { \# suffix derived form } \\ \begin{array}{c}\text { (tense /i/) } \\ \text { beauty }\end{array} & \text { (1ax /I/) } \\ & \text { beautifuz }\end{array}$

No such alternation exists in the case of free-standing words ending in 
/i/ and corresponding compounds. The vowe 1 in corresponding compounds behaves exactly like the vowel in the Eree-standing forms. Compare, for example, the forms in (7).

$$
\begin{aligned}
& \text { Underived word } \\
& \text { (tense /i/) } \\
& \text { beautyy }
\end{aligned}
$$

Compound

$$
\text { (tense /i/) }
$$

beauty-treatment

According to Allen (1978:122), these facts indicate that the rule responsible for the tensing or laxing of the vowel in question is sensitive to a structural difference in the immediate righthand environment of the target vowel in derivatives derived by \#boundary suffixation and compounds.

\section{b. $/ 1 /$ and $/ \mathrm{r} /$ syllabification}

According to Allen (1978:122-123), syllabification of $/ 1 /$ and $/ \mathrm{r} /$ occurs word-finally. In the case of corresponding forms derived by means of \#boundary suffixation, however, $/ 1 /$ and $/ \mathrm{r} /$ either do not syllabify, or

\begin{tabular}{|c|c|c|}
\hline Underived word & \# suffix derived form & Compound \\
\hline angle & angling & angle-inch \\
\hline$\left[æ_{\eta g} g 1\right]$ & {$\left[æ n g l_{1 n}\right]$} & {$[æ \eta g \partial \ln n c$} \\
\hline wonder & wondering & wonder-ape \\
\hline [wand.ər] & [wandron/wandorrm] & [wandəreyp] \\
\hline
\end{tabular}
they syllabify optionally. Furthermore, $/ 1 /$ and $/ r /$ always syllabify in compounds, even if followed by a vowel.

(8)

Once again, Allen's (1978:123) conclusion is that the internal boundary structure of compounds must be distinguished from the internal boundary structure of \#boundary suffix derivatives.

\section{c. Ericative voicing}

Allen (1978:124) points out that there is an alternation between voiceless and voiced fricatives in word-final position in some words and cor- 
responding derivatives formed by means of \#bondary suffixation. llowever, no stach alternation exists in the case of the lefthind constituent of corresponding compounds. Compare (9), for example.

Underived word
(voiceless
Iricative)
Iouse
[lows]

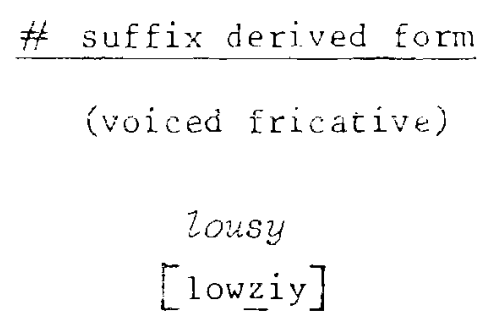

These examples show, once again, that the operation of certain phonological rules distinguishes between the internal boundary structure of compounds and the internal boundary structure of derivatives formed on the basis of \#boundary suffixation.

On the strength of the evidence surveyed above, Allen (1978:125) concludes that the internal boundary in compounds differs from the internal. boundary in derivatives formed by \#boundary suffixation. She (1978:126) proposes the following morphological structures in order to capture this difference:

(10) Inderived words

[\#WORD\#]

eg. [\#mercy \#]

Derivatives formed by Level II affixation rules

[\#[WORD $][\# \operatorname{SUFFIX}] \#]$

eg. $[\#[$ meroy $][\#$ fur $] \#]$

Compounds formed by Level III rules

$[\#[\#$ WORD\#] [\#WORD\#]\#]

eg. $[\#[\#$ mercy $][\#$ kizling $] \#]$ 
functioning as a constituent of a Level II derived word has a different morphological status from a "word" functioning as a constituent of a compound.

\section{(ii)}

\section{Morphological evidence}

The morphological evidence presented by Allen (1978:66) concerns the occurrence of negative prefixes in compound adjectives. According to Allen (1978:43), the prefix un-must be regarded as a Level II prefix associated with a \#boundary. As such, un- should not be able to attach to compounds, which is indeed the case.

$$
\begin{aligned}
& \text { *un-college-educated } \\
& \text { *un-factory-built } \\
& \text { *un-fuel-injected }
\end{aligned}
$$

The prefix non-, however, may attach to compound adjectives such as college-educated, factory-built, etc.:

$$
\begin{aligned}
& \text { non-college-educated } \\
& \text { non-factory-built } \\
& \text { non-fuel-injected }
\end{aligned}
$$

Allen (1978:73) thus concludes that the prefix non- is associated with a boundary stronger than \#. The facts in (11) and (12) above can now be accounted for: un- is a \#boundary prefix and, as a Level II rule, un- Prefixation precedes compounding; non-has a stronger boundary associated with it and therefore, non-Prefixation is considered a Level II rule. Being a Level III rule, non-Prefixation can apply to compounds, which are also formed by Level III rules.

According to Allen (1978:223), the phonological and morphological facts in (i) and (ii) above can only be explained within a morphological theory which includes the claim that Level III rules such as compounding rules must be ordered after all Level II affixation rules. Within Allen's (1978) morphological theory, the EOH constitutes such an ordering statement. 
As an ordering hypothesis, the EOH makes a number of predictions about the appearance of afrixes in certain morphological forms. These predictions, however, are not wholly unproblematic. One such problemaric prediction is that no Level II affixes can appear outside compounds formed by Level III rules. ${ }^{10)}$ It was shown that Allen (1978:121ff.) holds that the iriternal boundary in compounds is different from the internal boundary in derivatives formed by boundary affixation. Thus, if compounds contain a double internal word-boundary, it must be assumed that derivatives formed by \#boundary affixation contain a single internal word-boundary. Allen (1978:217) therefore proposes that the following distinctions be made:

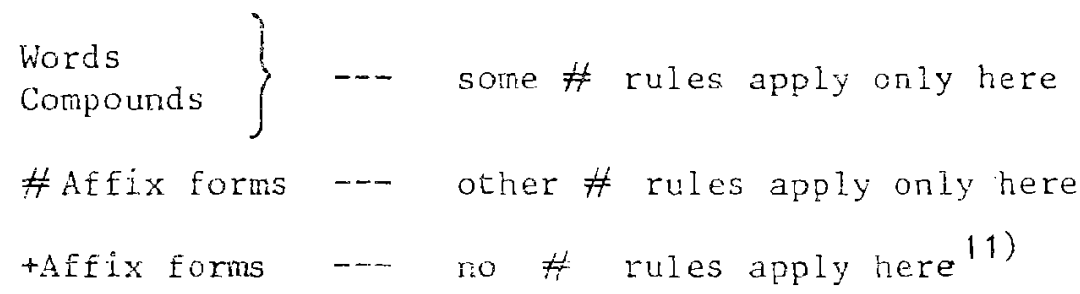

On the basis of the same types of evidence, Selkirk (1978:22), ${ }^{12}$ ) by contrast, claims that

\footnotetext{
"the segments preceding neutral [i.e. word-boundary ----

T.C.B.] affixes behave as if they were word-final." 13)
}

Therefore, Selkirk's word-boundary affixation ruies do not distinguish between the word-final morphological environment on the one hand, and the norphological environment internal to compounds and derivatives formed by \#bundary affixation on the other hand. According to Ailen (1978:216), Selkirk proposes that the following distinctions be made:

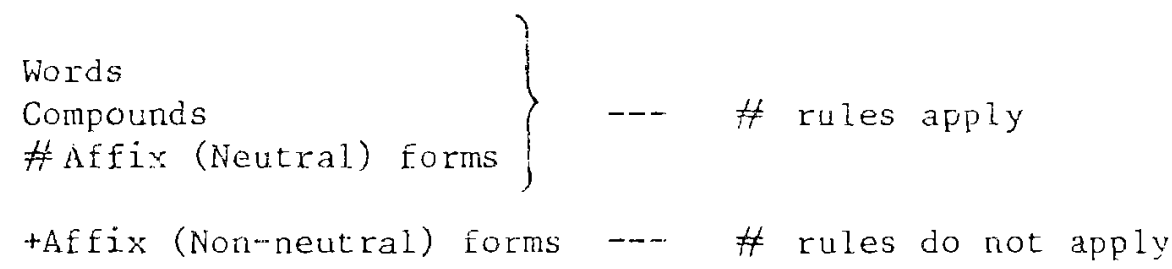

Selkirk (1978) argues for a morphological theory which Allen (1978:186) refers to as a "non-ordering" theory. 
Selkirh (1978:14) accepts the SPE distinction drawn between stress neutral and non-neutral affixes. Whereas neutral affixes are adjuncts to stems, non-neutral affixes are adjuncts to roots. She (1978:17) cites four fundanental properties which distinguish neutral affixes from non-neutral affixes in English. The property relevant to the present discussion is expressed by Selkirk's claim that, whereas neutral affixes can appear outside compounds, non-neutral affixes cannot. Given the distinction between stems and roots, ${ }^{14)}$ and the claim that neutral affixes attach to stems, whereas non-neutral affixes attach to roots, it is clear why Selkirk's morphological theory can be called a "non-ordering" theory. She does not need ordering claims to ensure that the neutral affixes always appear "outside" non-neutral affixes." In support of her claim that neutral, or \#boundary affixes can appear outside compounds, Selkirk (1978:21-22) presents some examples of morphologically complex words. Allen (1978:215) sees these examples as constituting a potential threat to the EOH and, hence, reanalyzes them to show that they are not real counterexamples to her own morphological theory.

\section{3}

\section{Predictions of the $\mathrm{EOH}$}

Before we consider Allen's reanalyses of the apparent counterexamples to the EOH, the predictions of her morphological theory must be examined in more detail. A first prediction which follows from Alien's (1978) morphological theory and which, in fact, is a prediction of the Ordering Hypothesis, can be formulated as follows: No + boundary affixes can appear outside \#boundary affixes.

The prediction (15) follows from the ordering claim of the Ordering Hypothesis, viz. that all Level II \#boundary affixation rules are ordered after all Level I +boundary affixation rules. Allen does not explicitly present (15) as a prediction of the EOH. However, in her (1978:18ff.) discussion of the prefixes $u n$ - and in-she argues that the Level I prefix in- can only attach to other Level I derived words. In (16)(a) below, for example, in-cannot co-occur with the Level II suffixes - ty, $-y$ and-iike. ${ }^{16)}$ However, in the forms (16) (b), in-may attach to words 
which are deriven by the Level I suffixes -ion, ity and -ate. Thus,

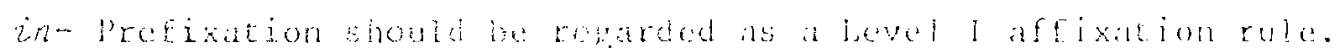

\begin{tabular}{|c|c|c|c|c|}
\hline \multirow[t]{6}{*}{$(16)$} & (a) & fritendiu & $\cdots \cdots$ & tinfriendiy \\
\hline & $\cdot$ & tuatey & $\cdots$ & *intuoky \\
\hline & & olizidike & $-\cdots \cdots$ & tinchizalike \\
\hline & $(5)$ & decision & $\cdots-$ & indecision \\
\hline & & $a b i t i z z$ & $\cdots \cdots$ & inobizity \\
\hline & & animate & $\ldots$ & incmonatee \\
\hline
\end{tabular}

By contrast, the suffix un- can attach to words derived by Level iI affixation rules. Compare, for exampie, the forms in (i7).

$$
\begin{aligned}
& \text { infriendiz } \\
& \text { unzucky } \\
& \text { uranizdizke }
\end{aligned}
$$

At a first glance, there seems to be some justification for the prediction presented in (15). As Alien (1978:215) notes, this prediction is essentially equivalent to the proposals incorporated in Siegel's (1974: 152) Ordering Hypothesis.

The second prediction of Mlien's morphologicai theory is described by her (1978:215) as "not controversial". This prediction follows from the second ordering clam of the EOH, viz. Hat all hevel III rules are ordered after ali Level $I$ and Level II affixation rules.

$$
\text { No level I tboundary affixes car appear outside compounds, }
$$
which axe formed by Level III rleles.

Aller (1978:215) notes that tboundary affixes do not appear outside compourds. They do, however, occur Ereely compound-internally. This is clear from the following examples presented by Allen (1978:215): 


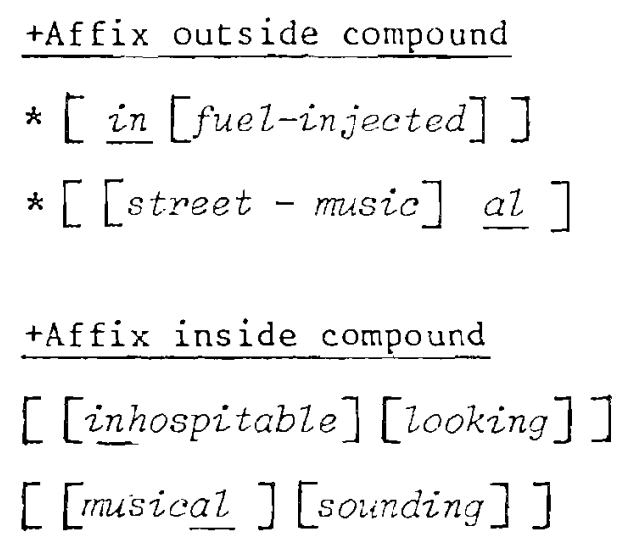

Allen (1978:215ff.) deals with the third prediction of the EOH in far greater detail. This prediction follows from the ordering claim expressed by the $\mathrm{EOH}$, viz. that all Level III rules are ordered after all level I and Level II affixation rules.

(20) No Level II \# boundary affixes can appear outside compounds, which are formed by Level III rules.

It was shown in $\S_{2}$ above that Allen (1978:75, 121ff.) argues, on the basis of phonological and morphological evidence, that a formal distinction should be drawn between Level II and Level III morphological processes. However, as Allen (1978:215) notes,

\footnotetext{
"The relationship of Level III morphological processes, especially compounding, to Level II word-boundary affixation rules is more complex."
}

Allen's problem is that there appear to be cases in which Level II affixes occur outside compounds. In the presentation of her morphological theory, Selkirk (1978:21) cites examples in which \#boundary affixes seem to appear outside compounds. ${ }^{17)}$ It is obvious that, if Selkirk's analysis should prove to be correct, such forms would constitute clear violations of the EOH. In an attempt to save the EOH, Allen (1978:215ff.) attempts to reanalyze the forms in question.

Of the various predictions made by Allen's morphological theory, the third one is both the most problematic and the most interesting. First, there are 
several. English words which apparently conflict with this prediction and which have to be dealt with individually by Aljen. Secondy, the prediction does not seem to be bone out by data from languages other than English. In the rest of this paper, therefore, I will concentrate on the third prediction of Allen's morphological theory.

\section{Allen's defence of the EOH}

\section{1 General.}

In addition to the apparent counterexamples presented by Selkirk (1978: 21), Allen (1978:224ff,) herself cites a number of forms which pose a threat to the $\mathrm{EOH} .^{18}$ ) Before proceeding with a discussion of Allen's handing of specific apparent counterexamples to the EOH, let us first consider her reaction to the apparent counterexamples in general.

Botha (1981a:408-409) lists seven fundamental ways in which a scientist may react to criticism brought against a hypothesis or theory. ${ }^{19)}$ The choice of an appropriate form of reaction is co-deternined by the scientist's judgment of the relevance and force of the criticism brought against his theory.

Some of the strategies used by Allen in clefence of the EOH against the putative counterexamples represent the form of reaction called "protection" by Botha (1981a:413-4î). "Protection", according to Botha (198ia: 409), entails that

\footnotetext{
"the scientist takes steps to protect H [i.e. a hypothes is - T.C.B.] or T [i.e. a theory ... T.C.B.] from the criticism without eliminating its defect(s) in any direct way."
}

According to Botha (1981a:414), this type of reaction is aimed at retaining a criticized hypothesis by taking certain steps. These steps involve the formulation of auxiliary hypotheses wich protect the defective hypothesis from the criticism. Auxiliary hypotheses are either ad hoc or non-ad hoc in nature, ${ }^{20)}$ depending on whether the protective devices in terms of which the claims are made are objectionable or non-objectionable. 
According to Botha (1978:3), "profective devices" may be characterized as

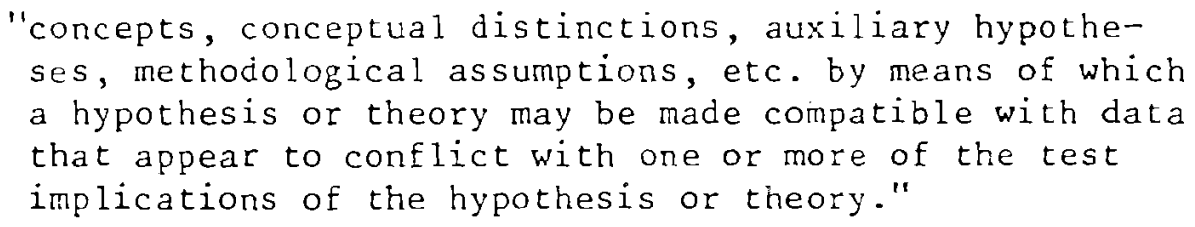

Botha (1978:19) states that a protective device is conventionally considered to be objectionable if it can be used to make claims which have to be assigned the status of ad hoc auxiliary hypotheses. Conversely, a protective device is non-objectionable if it can be used to make claims that can be assigned the status of non-ad hoc auxiliary hypotheses.

As was claimed above, Allen's (1978) strategy for defending the EOH entails protecting it from refutation. The steps she takes, crucially do not involve any modifications to the hypothesis, but serve to render the criticized EOH consistent with the linguistic data that constitute the potential counterexamples. The question that has to be answered here, is whether Allen's strategy of protection is objectionable or non-objectionable. In order to do this, consideration will have to be given to the putative counterevidence in conjunction with the various protective devices which Allen (1978) employs.

Most of the putative counterexamples to the EOH which Allen (1978:224ff.) deals with come from (Selkirk 1978). Selkirk does not present them as counterexamples to the EOH, but Allen regards them as posing a threat to her hypothesis. The remaining putative counterexamples are mentioned by Allen herself. All the examples involve the occurrence of an affix, specifically a \#boundary affix, outside a compound. As was previously shown, the ordering claim expressed by the EOH explicitly prohibits the attachinent of a level II, \#boundary affix outside a compound. 21)

The putative counterexamples to the EOH fall into two classes, viz. (i) words in which prefixes appear outside compounds, and (ii) words in which suffixes appear outside compounds. Examples of words in which prefixes occur outside compounds are the following: 
(23) $\quad 4 n-$

$$
\begin{aligned}
& \text { [un-[hen pecked] }] \\
& \text { [un- [ God feaming }]]
\end{aligned}
$$

(22) to re-air-condition

to pre-aix-condition

to pre-proof-read

to re-proof-read

re-type-write

re-tape-record

pre-tape-record ${ }^{23}$ )

Selkirk (1978:21) also presents the following examples in which suffixes occur outside compounds:

(23) $-f u z$

$$
\begin{aligned}
& [\text { [fingen tip }]-f u l] \\
& {[[\text { tug boat }]-f u z]} \\
& \text {-Zess } \\
& [\text { motor cyole }]-\text { Less }] \\
& [\text { [sun onine }]-\text { Less }]
\end{aligned}
$$

-ness

$[[[$ bight fist $]$-ed $]$-ness $]$

[ [home sick] -ness] 


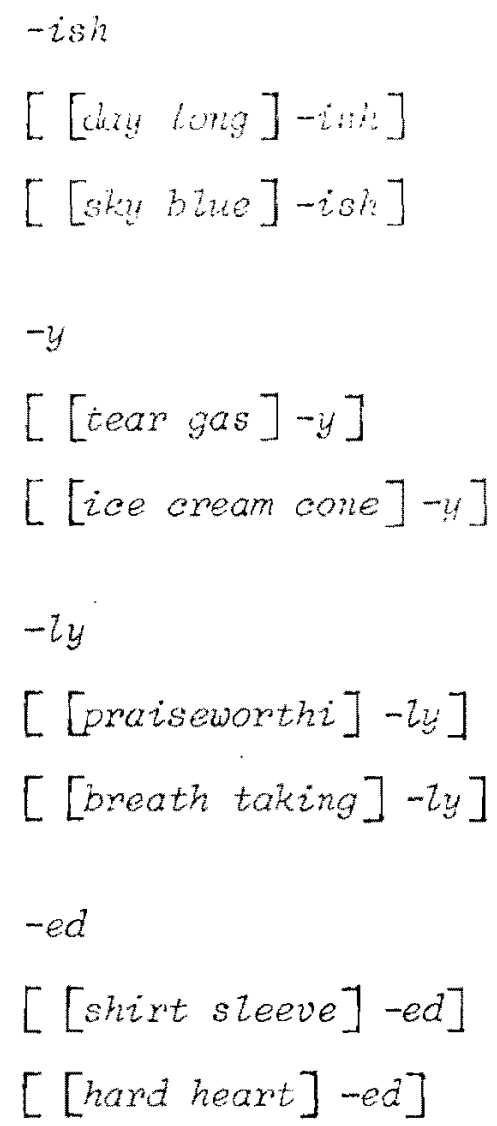

The various protective devices which Allen employs in reanalyzing these putative counterexamples to the EOH, will be examined in the following paragraph.

\subsection{Prefixes occurring outside compounds}

As was noted in \$3, the EOH predicts that \#boundary affixes cannot occur outside compounds. According to A1len (1978:222-224), this prediction is borne out by examples such as the following:

(24) un\#

\begin{tabular}{|c|c|}
\hline unabsorbent & xun- $[$ anmabsonbens] \\
\hline unfilited & $x_{i n}-[$ down-filled] \\
\hline \multicolumn{2}{|l|}{ re\# } \\
\hline re-dive & $x_{y} x_{e}-\left[s b_{y}-d i v e\right]$ \\
\hline re-clean & *re- [uacum-ciean] \\
\hline
\end{tabular}


de\#

Verb: de--magnetize xde-[hand-momotinc]

Noun: de-mast *a:- [fore-nk:t]

$\operatorname{maz\# }$

mal-formation

what - [bone-formation]

mar-adjustment tmal- [timing-adjustment]

hyper\#

hyper-extension

*hyper - [ruscie-extension]

$m i s \#$

mis-pronunciation

Anis - [vowel-pronunciation]

mis-judgment *mis-[court-judgment]

The examples above appear to indicate that the \#boundary prefixes may not attach to compounds, exactly as predicted by the EOH.

\subsubsection{The prefixes re- and pre-}

Although the prefixes un-, re-, de-, mal-, hyper- and mis- do not appear outside compound verbs, as illustrated in (24) above, there seem to be some cases in which prefixes can appear outside compounds. On the strength of the occurrence of derivatives based on compound verbs such as those in (21) and (22) above, Allen (1978:224, 231) concedes that the prefixes reand pre- do appear to attach externally to some compound verbs. The derivatives in question are repeated in (25) for the sake of convenience.

$$
\begin{aligned}
& \text { re-air-condition } \\
& \text { pre-air-condition } \\
& \text { pre-proof-read } \\
& \text { re-proof-read } \\
& \text { re-type-write } \\
& \text { re-tape-record }
\end{aligned}
$$


pre-tape-record

re-up-grade

Because both re- and pre- attach only to verbs, the bracketing of the examples in (25) should be similar to the bracketing which Allen (1978: 225) proposes for re-air-condition and pre-proof-read.

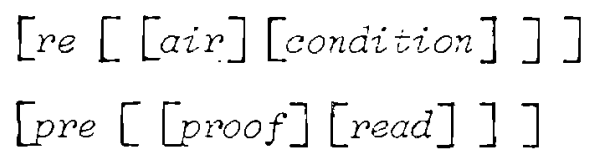

According to Allen $(1978: 225)$, it is quite clear that the verbs in (25) in which the prefixes re- and pre- appear outside compounds, constitute violations of the EOH. Consequently, she (1978:225-232) has to defend the EOH in one way or another. The strategy which Allen (1978:225-232) employs is to deny these forms the status of actual counterexamples. This she achieves by drawing a conceptual distinction between compounds formed by regular Level III rules and compounds formed by back-formation. Hence, she (1978:231) argues that

\footnotetext{
"These examples [i.e. the examples in (25) above -..T.C.B.] violate the Extended Ordering Hypothesis only if the Level II prefixes re- and pre- attach externally to Level III derived compound verbs. But I have argued that compound verbs such as to air-condition, to typewrite, to tape-record are not Level III derived compound verbs, but arise via a phenomenon limited to items in the permanent lexicon. The occurrence of external prefixes in compound verbs derived by back-formation is therefore not a violation of the Extended Ordering Hypothes is."24)
}

Allen (1978:226) points out that the fact that the compounding rules for nouns and adjectives are overgenerating rules would lead one to expect the rule of compound verb-formation to be an overgenerating rule as well. 25) According to her $(1978: 226)$, however, this is not the case. This rule does not generate a set of "possible compound verbs". The verbs to air-condition, to proof-read, to ghost-write, to joy-mide, etc. do not exemplify a productive morphological pattern. According to 
Allen (1978:226), they belong to a very restricted class of compounc verbs. To illustrate her point, she cites related verbs such as those in (27) claiming not only that these verbs are non-occurring words, but also that they are morphologically impossible.

$$
\begin{aligned}
& \text { *to waten-condition } \\
& \text { to print-read } \\
& \text { *to student-write } \\
& \text { *to train-ride }
\end{aligned}
$$

Allen thus argues that there is no compound verb formation rule in English.

The hypothesis that compound verbs in English differ from other conpounds in that the former are not formed by Level III rules, is the basis of a first strategy to protect the EOH from refutation. The argument which forms the basis of this strategy, may be reeonstructed as follows :

(28) (a) There is no Compound Verb Formation rule which directly generates compound verbs in English.

(b) Compound verbs in English are formed by means of one of two processes, viz. back-formation from items listed in the permanent lexicon and zero-derivation.

(c) The rOH does not apply to morphological processes operating within the permanent lexicon.

(d) Thus, the cases where prefixes appear outside compound verbs are not actual counterexamples to the $\mathrm{EOH}$.

The (b) part of (28) is supported by two supplementary arguments. The first one concerns the nature of back-formation. Allen (1978:227-231) argues that verbs such as to air-condition and to proof-read are formed in the following way: 


\section{"Why can forms such as air-condition and tape-record occur as verbs, while the forms water-condition and book-record are not possible compound verbs. The answer lies in the fact that verbs such as air-condition and tape-record are associated with lexicalized nominal compounds; i.e. aix- conditioner, tape-recorder. Notice that to air-condition does not mean 'to condition the air (by any means)', but rather 'to use an air-conditioner', where 'air-conditioner' itself has a highly specialized meaning ... By contrast, water-conditioner, book-recorder are possible compound nouns but are not lexicalized compounds with idiosyncratic meanings. Just in those cases where there are no lexica- lized compound nouns, there are also no related compound verbs: *to water-condition, tto book-record ...}

The traditional analysis of compound verbs [such as to air-condition and to proof-read -.- T.C.B.] is that they are back-formations. That is, a verb such as to aircondition is derived via a process of re-analysis and affix-dropping from a related compound noun or adjective, the second element of which must be deverbal. For example, the compound nouns air-conditioner, $\ldots$, stage-manager, $\ldots$, are bracketed as shown below.

$$
\begin{aligned}
\left.\left.(310)[\text { stage }]_{N}[\text { manage }]_{\mathrm{V}} \text { er }\right]_{N}\right]_{N} \\
{\left[[\text { air }]_{N}\left[[\text { condition }]_{\mathrm{V}} \text { er }\right]_{N}\right]_{N} }
\end{aligned}
$$

The presence of the suffix -er, which attaches to verbs, can force a re-analysis; e.g.

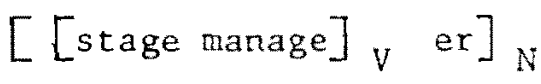

$$
\begin{aligned}
& \left.[\text { [air condition }]_{\mathrm{V}} \text { er }\right]_{\mathrm{N}}
\end{aligned}
$$

... As the data ... show, back-formation is applicable only to lexicalized compounds ... In other words, back-formation is a phenomenon which is limited to items in the permanent lexicon, and does not apply to compounds formed by leve1ordered, overgenerating rules of morphology."

Allen's argument as regards back-formation, can be reconstructed as follows:

(29) (a) There is no rule of Compound Verb Formation in English.

(b) Compound verbs such as to air-condition and to proof-read have lexicalized compounds associated with them. 
(c) Back-tormation applies only to lexicalizod compounds listed in the permanent Lexicon.

(d) Thus, compound verbs such as to air-condition and to proof-read are formed via back-formation from itcms listed in the Permanem Lexicon.

The second supplementary argument in support of (28)(b), concerns the process of "zero-derivation". The process of zero-derivation is invoked by Allen (1978:231-232) to derive compound verbs fron related compound nouns which are not lexicalized.

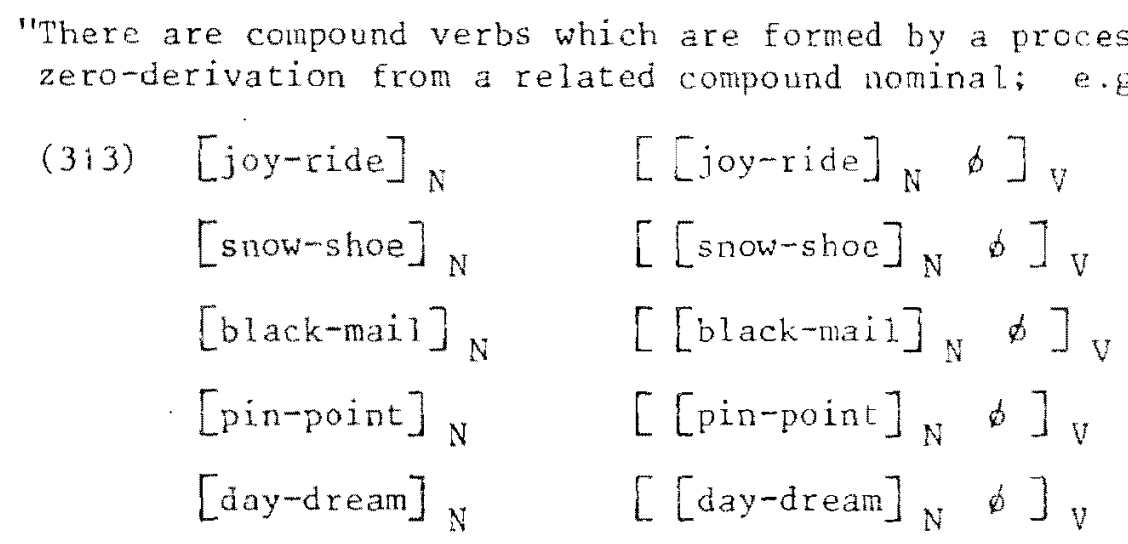

... it will be argued that zero derivation is a component of the level-ordered morphology. Therefore, the Extended ordering Hypothesis is relevant to zero-derived compounds, and predicts that leve? II \#boundary affixes should not appear outside zcro-derived compound verbs. This prediction seems to be borne out by the facts, as illustrated by the following examples.

$$
\begin{array}{ll}
\text { "re-black-mail } & \text { re-mail } \\
\text { "re-pin-point } & \text { re-point } \\
\text { "re-day-dream } & \text { re-dream." }
\end{array}
$$

Allen (1978:281) in fact claims that zero-derivation is a jevel III morphological process. Her argument concerning compound verbs formed by zero-derivation is reconstructed in (30).

(30) (a) Zero-derivation is a Level II morphological process.

(b) No Level In \#boundary affixes should appear outside zero-derived compound verbs. 
(c) The \#boundary prefixes re- and pre- may not appear outside-compound verbs such as joy-ride, blackmail, day-dream, etc.

(d) Thus, the compound verbs joy-xide, blackmait and day-dream are formed by zero-derivation.

According to Allen (1978:232), only those compound verbs that are formed by means of back-formation can be prefixed by re- and pre-.26) These cases, however, fall outside the domain of the EOH. The zeroderived compound verbs which fall in the domain of the $\mathrm{EOH}$, obey the restrictions of this hypothesis. By employing the strategy of reanalysis of the problematic data, Allen thus attempts to protect the EOH from refutation by forms such as to re-air-condition.

In the preceding discussion it became clear that Allen needs additional assumptions in order to protect the EOH from the apparent counterexamples in (25) above. Allen's (1978:224ff.) strategy of protecting the EOH by reanalyzing certain compound verbs as back-formations, depends heavily on the distinction between the Conditional and the Permanent Lexicon. The strategy itself is not wholly unproblematic either. A first problematic aspect of the strategy is Allen's conception of lexicalization. It is not clear on exactly what grounds she distinguishes between lexicalized and non-lexicalized forms. Consider, for instance, her discussion of the occurrence of the prefix re- outside compound verbs, as in to re-air-condition.

As was noted above, Allen (1978:227) regards compound verbs such as to air-condition to be back-formations from related lexicalized compound nouns. She (1978:228) claims that air-conditioner, in contrast to water-conditioner, is lexicalized, and as such has "a highly specialized meaning". According to her, to air-condition does not mean "to condition the air", but rather "to use an air-conditioner". However, she does not explain why to air-condition cannot mean "to condition the air" if to condition has the conventional meaning "to put into the required state".27)

A related problen concerns the grounds on which it is decided whether or not a given word is lexicalized. Thus, it is not quite clear on what grounds Allen decides that nouns such as air-conditioner and 
proof-reader have "highly specialized meanings". In order co substantiate claims such as these, Allen has to formulate explicit criteria on the basis of which it can be decided whether a given form is lexicalized or not. Her discussion proceeds in the absence of such criteria. The problem is clearly illustrated by the form air-conditioner. According to Webster's 28 ) (1961:46), an air-conditioner is "one that airconditions". The meaning of this form, according to this dictionary at least, thus seens to be fully compositional.

A second problematic aspect of Allen's reanalysis concerns the notion 'back-formation'. Linguists such as Marchand (1969) and Aronoff (1976) regard back-formation as a process which has mainly diachronic relevance. Compare the following remarks by Marchand $(1969: 3)^{29)}$ :

\footnotetext{
"The process called backderivation (backformation) has often diachronic relevance only. That peddle vb. [i.e. 'verb'--T.C.B.] is derived from peddler sb. [i.e. 'substantive' -- T.C.B.] through reinterpretation is of historical interest. For synchronic analysis, however, the equation is peddle : peddler = write : writer, which means that the diachronic process of backderivation does not affect the derivative correlation for present-day speakers who do not feel any difference between the relationship write : writer on the one hand and peddle : peddler on the other."
}

According to Jackendoff (1975:649,650), a formerly non-existent word such as retribute, for instance, enters the language by means of the process of back-formation from, say, retribution. But once retribute is in the lexicon, a restructuring is possible, resulting in retribute being regarded as the basic and retribution as the derived form. This account, in Jackendoff's opinion, captures the fact that a word formed by means of back-formation ceases to be recognized as such by speakers of English.

Allen does not adduce a single argument showing that the ideas of Marchand, Jackendoff and Aronoff regarding back-formation are untenable. In fact, it seems quite plausible to assume that speakers of English regard a noun such as aimanditioner as a derivative formed by -er Suffixation on the basis of the verb air-condition. The opposite view, viz. that speakers regard air-conditioner as the base from which the verb air-condition is derived, seems considerably less plausible. It 
is undeniably so that the rule which attaches agentive -er in English is productively involved in the derivation of a large number of agentive nouns in English. An account of the forms air-condition: aipconditioner such as that of Allen (1978), thus seems to lack the appropriate grounding. Moreover, it is doubtful whether Allen's analysis of compound verbs as back-formations is the best of the alternatives available within her own framework. She (1978:198ff.) proposes a system in terms of which morphological features may be assigned to words in the Conditional Lexicon. These features specify whether or not certain words and their related derivatives may be selected by the Lexical Insertion transformations. She (1978:200) proposes that the feature [-Lexical Insertion;Strong] (or [-LIS]) be assigned to words derived by non-productive, semantically non-compositional word formation processes. Given that the compound verb formation rule is a non-productive rule, one may ask why Allen cannot merely assign the feature [-IIS] to the compound verbs to air-condition and to tape-record? According to her $(1978: 200)$, the fact that an item in the Conditional Lexicon is marked [-LIS] does not prevent it from participating in, what she calls, "further morphological derivation". Thus, the productive rule of -er Suffixation could apply to the verbs to air-condition and to tape-record to form the nouns air-conditioner and tape-recorder. However, Allen does not consider such an analysis at all. It seems, then, that Allen's reanalysis of certain compound verbs as backformations is not particularly well-motivated, even within her own framework. Consequently, the hypothesis that compound verbs are formed by back-formation and zero-derivation, should be regarded as an ad hoc auxiliary hypothesis, introduced for the sole purpose of protecting the EOH. Given these problematic aspects of Allen's protection of the EOH, the apparent counterexamples in (25) above must be regarded as real counterexamples to the hypothesis.

\subsubsection{The prefix un-}

The occurrence of the prefix un- outside compounds, as in (31) below, also appears to contradict the second ordering claim of the EOH. The following cases are presented by Selkirk (1978:21): 
(31)

$$
\begin{aligned}
& {[\text { in }[\text { hen-pecked }]]} \\
& {[\text { m [ }[\text { od-feaning }]]}
\end{aligned}
$$

Allen (1978:18ff.) argues that un- is a Level II \# boundary prefix. Consequently, according to her theory (1978:222), un- cannot appear outside compounds. Allen presents the following examples in support of this claim:

$$
\begin{aligned}
& *_{\text {un }}[\text { [fuel-injected }] \\
& *_{\text {un }}-[\text { sure-footed }] \\
& *_{\text {un }}-[\text { berry-gathering }] \\
& *_{\text {un }}-[\text { home-made }]
\end{aligned}
$$

Allen does not regard examples such as those of (31) as posing a threat to the EOH. She $(1978: 288 \mathrm{n} .17)$ argues as follows:

"I find both examples [i.e. the examples in (31) -.. T.C.B.] extremely marginal. When a reasonable number and variety of compound adjectives is examined, it becomes clear that non- attaches quite freely, but that un- is very generaliy excluded [from attaching to compounds -- T.C.B.]."

The claim that forms in which the prefix un- appears outside a compound are "extremely marginal", forms the basis of a second device which Allen employs to protect the EOH from potential counterexamples such as un-hen-pecked. Allen's argument can be reconstructed as follows:

(33) (a) Unlike non-, un- does not attach "quite freely" to compounds .

(b) The cases in which un-occurs outside compound adjectives are extremely narginal.

(c) Thus, the cases in which un-occurs outside compound adjectives do not constitute a violation of the EOH.

Alien's treatment of the potential counterexamples in (31) is highly unsatisfactory. She denies these forms the status of real counterexamples to the EOH but makes no attempt to provide an acceptable explana- 
tion for the fact that these forms do occur in the language. Furthermore, the meaning of expressions such as "a reasonable number and variety of compound adjectives", "quite freely", "very generally" and "extremely marginal" is unclear. For example, how many examples can be considered to be a "reasonable number" of examples? The hypothesis that the cases in which un- appears outside compound adjectives are extremely marginal and cannot be regarded as counterexamples to the EOH, thus seems to be entirely ad hoc. Because Allen's protection of the EOH against potential counterexamples such as un-hen-pecked and un-God-fearing is not convincing, these forms too must be regarded as real counterexamples to the $\mathrm{EOH}$.

This concludes the discussion of Allen's treatment of a first class of potential counterexamples to the EOH, viz. forms in which prefixes occur outside compounds. I have shown that Allen does not succeed in giving a satisfactory explanation for the apparent occurrence of the suffixes re-, pre- or un- outside compounds. Thus, despite her attempts to do so, all the examples under discussion must still be regarded as counterexamples to the $\mathrm{EOH}$.

\subsection{Suffixes occurring outside compounds}

\subsubsection{The suffix $-f u l$}

According to Allen (1978:234), the occurrence of the \#boundary suffix -ful outside apparent compounds, as in (34) below, appears to constitute a violation of the EOH.

$$
\begin{aligned}
& {[[\text { finger tip }]-f u l]} \\
& {[[\text { tug boat }]-f u l]}
\end{aligned}
$$

Allen (1978:235) refuses to regard the examples in (34) as counterexamples to the EOH. She (1978:234-235) states that 


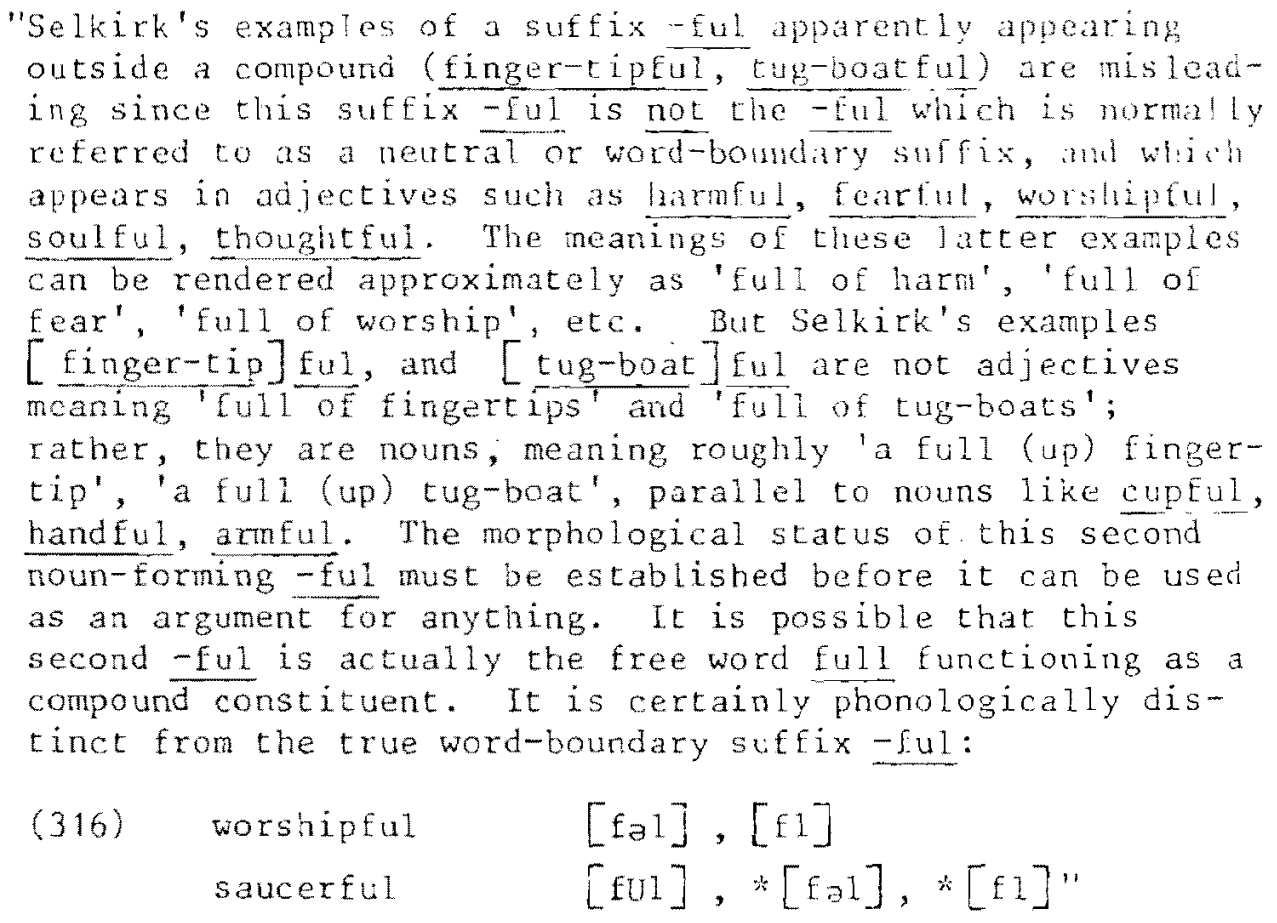

Allen (1978:234) notes that there are two different morphemes, -fuz, and fix $\tau_{2}$, which have different properties. A comparison of the properties of $-f u l_{1}$ and $f u \vec{l}_{2}$ reveals the following differences:

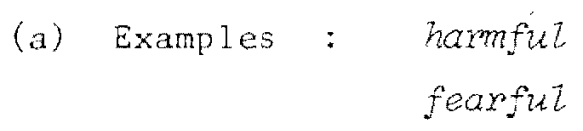

(b) Semantics : "full of $x "$

(c) Morphology: (i) appears in adjectives

(ii) does not attach to compounds 30$)$

(d) Phonology : (i) has zero stress

(ii) phonetic representation: [E1] [fəl]

$$
\text { fut }
$$

(a) Examples : firgon-tipfuz tug-boatful

(b) Semantics : "a full (up) $x$ "

(c) Morphology: (i) appears in nouns

(ii) attaches to compounds

(d) Phonology : (i) has secondary stress

(ii) phonetic representation: [ful] 
Thus, according to Allen (1978:235), the morpheme ful 2 which may attach to compounds, as in finger-tipful and tug-boatful, is actually the free word fulz. This claim forms the basis of an argunent which may be reconstructed as follows:

(36) (a) $-f u l_{1}$ and $f u l_{2}$ represent two different morphemes.

(b) $-f u Z_{1}$ is a \#boundary suffix which (i) means "full of $x^{\prime \prime}$, (ii) appears in adjectives, (iii) does not attach to compounds, (iv) has zero stress and (v) is pronounced $[\mathrm{El}]$ or $[\mathrm{Fal}]$.

(c) $\mathrm{ful}_{2}$ is a morpheme which (i) means "a full (up) x", (ii) appears in nouns, (iii) attaches to compounds, (iv) has secondary stress and (v) is pronounced [fUl].

(d) The morpheme - ful which appears in finger-tipful has all the properties of $\mathrm{fut}_{2}$ which is not a \#boundary suffix.

(e) Thus, forms such as finger-tipful and tug-boatful in which $\mathrm{fuz}_{2}$ occurs outside compounds do not constitute a violation of the EOH.

Whereas $-\mathrm{ful}_{1}$ is a suffix which is attached by a Level II \#boundary suffixation rule, $\mathrm{ful}_{2}$ is an independent word which is attached by a Level III compounding rule. According to Allen (1978:235), the appearance of $\mathrm{ful}_{2}$ outside compounds (eg. finger-tipful) is therefore no more surprising than the existence of doubly compounded words such as shoe-box label and blackboara eraser.

Thus, Allen protects the EOH by arguing that Selkirk (1978:21) has misanalyzed the forms finger-tipful and tug-boatful. According to Allen (1978:234), Selkirk has failed to note the differences between the word full which attaches to compounds and the suffix -ful which appears in derivatives. If these differences are taken into consideration, the $E O H$ is in no way contradicted by the relevant facts. 
to compounds is quite convincing. Nida (1946:82, 89) has made similar observations about the differences between the suffix -ful and the Eree word fuzz. 31)

\footnotetext{
"This form [i.e. -fuz as in harmful -- T.C.B.] must be distinguished from the allomorph -Eul which occurs in handful, hatful ..., and which has a different type of juncture and a secondary stress rather than a zero stress." 32 )

"Allomorph 2 [i.e. -fuz as in handful -.- T.C.B.] combines in the same way as do compounding roots."33)
}

We can conclude, then, that the hypothesis concerning the word status of the ful which appears outside compounds, is well-supported and therefore non-ad hoc.

\subsubsection{The suffix-Less}

According to Allen (1978:236), Selkirk's (1978:21) account of forms such as those in (37), in which the suffix - less appears outside compounds, represents another case of misanalysis:

$$
\begin{aligned}
& {[[\text { motor cucle }]-\text { less }]} \\
& {[[\text { sun shine }]-\text { less }]}
\end{aligned}
$$

Allen attempts to analyze the -less cases in the same way as the cases with -ful. She $(1978: 236)$ argues as follows:

\footnotetext{
"Since there is also a free word less it is possible that these are also cases of compound formation. As in the case of -ful, the true word-boundary suffix -less and the -less which appears outside of compounds are phonologically distinct. In the true word-boundary suffix -1ess, the vowel of the suffix is a reduced vowel: fatherless [-1as], moneyless $[-1 \partial s]$, meaningless $[-1 \partial s]$. Where-less attaches outside a compound, however, it can be stressed and unreduced, $[-1 \varepsilon s]$. These facts make it doubtful that forms such as motor-cycle-less contain the word-boundary suffix - less."
} 
The claim that the -less which appears outside compounds is the free word less, forms the basis of an argument representing yet another device to protect the EOH fron refutation. The argument may be reconstructed as follows:

(38) (a) There are two morphemes less 1 and less 2 .

(b) -less, is a \#boundary suffix, of which the vowel is a reduced vowel, viz. $[-1 \partial s]$.

(c) Zess 2 is a morpheme of which the vowel is stressed and unreduced, viz $[-1<s]$.

(d) The morpheme -less which appears in motor-cycle-less has the properties of less 2 and is not a \#boundary Suffix.

(e) Thus, cases such as motor-cycle-less and sun-shine-less, where less ${ }_{2}$ occurs outside compounds, do not constitute violations of the $\mathrm{EOH}$.

Like fur 2 , less ${ }_{2}$ is regarded by Allen as an independent word which can be attached to other simple or compound words by means of a Level III compounding rule.

However, Allen's protection of the EOH from potential refutation by examples such as motor-cycle-less and sun-shine-less is not quite convincing. The major problem with Allen's analysis is that she does not provide adequate evidence for the claim that a distinction should be made between two morphemes less. The only evidence that Allen (1978: 236) presents in support of this distinction, is phonological evidence. According to her, the vowel of the -less attaching to compounds is stressed and unreduced, i.e. [1हs].

According to Webster's (1961:1296), the word 2.63 .3 is pronounced "\les\" as in bet and bed. The pronunciation of the suffix-less, by contrast, is "\İs\", as in habit and duchess. This distinction corresponds to Allen's (1978:236) distinction between [1ts] and [los]. According to Webster's (1961:1296), the meaning of the word less is "to a lesser extent or degree", whereas the suffix -less means 
"destitute of, not having, Eree Erom". Allen provides no scmantic evidence in support of her proposed distinction between two instances of less, but her claims have certain semantic consequences. In ciaiming that the free word less attaches outside compounds as in sun-sinine-lesi, Allen is implicitly claiming that the meaning of the word zess is added to the meaning of the compound sun-shine. Thus, it is predicted that a complex word such as sun-shine-less will mean sometining like "sun-shine, but to a lesser extent or degree", or "not so much sun-shine". However, sun-shine-less does not have this meaning. Rather, it means "without sun-shine". The meaning of -less in sun-shine-less is identical to that of the suffix-less. Thus, it follows that it is in fact the suffix - Zess which attaches to sun-shine. Allen's claims about the phonetic form of the zess which appears outside compounds thus makes predictions about its morphological status and its meaning that are incorrect. Allen also fails to demonstrate, as she (1978:236) did in the case of -ful, that the \#boundary suffix-less does not attach to compounds. The hypothesis that the -less which attaches to compounds is the vorc less, is completely ad hoc. It may be concluded, therefore, that it is in fact the \#boundary suffix - Less which occurs outside the compounds in (37). 34) In sum, Alten fails to protect the EOH from potential refutation by the counterexamples in (37). The occurrence of the \#boundary suffix - Less outside compounds, constitutes a clear violation of the EOH.

\subsubsection{The suffixes -ness, $-i$ sh and $-y$}

The third class of potential counterexamples which Selkirk (1978:21) provides, includes the forms in (39). These examples illustrate the attachment of the suffixes -ness, $-i s h$ and $-y$ outside compounds.

(39) -ness: $\begin{aligned} & {[\text { [tight fisted }] \text {-ness }] } \\ & {[\text { [home sick }]-\text { ness }] } \\ - \text { ish : } \quad & {[[\text { sky blue }]-i s h] } \\ & {[[\text { day long }]-i s h] } \\ -y: \quad & {[[\text { tear gas }]-y] } \\ & {[[\text { ice cream cone }]-y] }\end{aligned}$


In all the examples above, an affix occurs outside a compound. However, Allen (1978:237) denies forms containing the suffixes -ness, $-i s h$ and $-y$ the status of true counterexamples to the EOH. She (1978: 236-237) bases her argument on the claim that these suffixes may attach to "non-morphological units", as she calls them. Consider the following examples in which the suffixes -ness, -ish and $-y$ allegedly at tach to phrases:

$(40)$

$$
\begin{array}{ll}
\text {-ness: } & {[\text { black and blue }] \text { ness }} \\
- \text { ish : } & {[\text { blood-and-thunder }] \text { ish }} \\
-y: & {[\text { spider's web }] \text { y. }{ }^{35)}}
\end{array}
$$

Allen (1978:238) notes that the occurrence of a form such as spider's webby appears to be totally inconsistent with the claim that inflectional processes are syntactic phenomena which follow all derivational processes. According to her $(1978: 238)$, the bracketed phrases in (40) have lexicalized meanings. As such, they are listed in the Permanent Lexicon. Thus, the fact that suffixes attach to them is completely irrelevant to the evaluation of the EOH. However, these suffixes do behave extraordinarily in that they are allowed to attach to idiomatic phrases listed in the Permanent Lexicon. Allen (1978:239) calls the process by means of which affixes are attached to items in the Permanent Lexicon, "stretchable suffixation". According to her (1978:239), only a few derivational suffixes may "stretch" their domain of application so as to include items in the Permanent Lexicon.

By claiming that the suffixes -ress, $-i s h$ and $-y$ are stretchable suffixes, Allen (1978:239ff.) attempts to account for the examples in (39). Let us consider the steps taken by Allen (1978:240-241) to deny these examples the status of actual counterexamples to the EOH.

\footnotetext{
"The examples ... clearly show that where the suffixes -ness, -ish and $-y$ attach to compounds, they are attaching to lexicalized compounds, that is, they attach to compounds which are non-compositional and which must consequently be listed in the permanent 1 exicon...

I have already shown that it is necessary to make some kind of special statement about -ness, -ish and $-y$ to the effect
} 
that they may attach to lexicalized phrases. This necessary statement also explains why the suffixes in question attach to lexicalized compounds, bul not to productive compounds. Indeed, given the independent establishment of strctchable suffixation, the null hypothesis would be that stretchable suffixation is applicable to all items in the permanent lexicon. The fact that the suffixes -ness, - ish and $-y$ attach to lexicalized compounds, but not to productive $\overline{c o m}-$ pounds, is thus completely in accord with the independently established notion of stretchable suffixation. Finally it should be clear that the attachment of -ness, -ish and $-y$ to lexicalized compounds can no longer be construed as a violation of the Extended Ordering Hypothesis."

Allen's argument involving the notion of 'stretchable suffixation' may be reconstructed as follows:

(41) (a) The EOH does not apply to morphological processes operating within the Permanent Lexicon.

(b) The forms to which -ness, $-i s h$ and $-y$ attach as stretchable suffixes are in the Permanent Lexicon.

(c) Thus, the existence of forms such as tight-fistedness, sky-blue-ish and tear-gas-y cannot be construed as a violation of the EOH.

Allen (1978:240) notes that the suffixes-ness, $-i s h$ and $-y$ cannot attach to semantically compositional compounds formed by fully productive compounding rules. She presents examples such as the following to illustrate her point:

$$
\begin{aligned}
& \text { *Large-fistedness } \\
& \text { *death-dayish } \\
& \text { *deer-fieshy }
\end{aligned}
$$

By positing the notion of stretchable suffixation, Allen thus attempts to exempt the attachment of the \#boundary suffixes -ness, -ish and -y to compounds from the ordering restrictions imposed by the EOH. Stretchable suffixation is a phenomenon limited to the domain of the Permanent Lexicon. As such, it falls outside the scope of predictions about morphological well-formedness made by the EOH. 
Allen's (1978:238-240) reanalysis of the counterexamples in (39) above is not without problems, however. One of the basic problems of this reanalysis concerns her use of the notion 'lexicalized'. The factual basis of the reanalysis is the claim that the phrases and compounds to which the suffixes -ness, $-i s h$ and $-y$ attach, are lexicalized forms. As noted with reference to compound verbs in $\$ 4.2 .1$ above, it is not clear what criteria Allen adopts to distinguish between lexicalized and non-lexicalized forms. An examination of the examples presented by Allen $(1978: 240)$ in support of the claim that -ness, -ish and $y$ attach to lexicalized compounds only, reveals that the notion 'lexicalized' with which she operates is rather obscure. The list of lexicalized compounds which Allen (1978:240) presents, includes compounds that are by no means obviously non-compositional in meaning. The following compound, for example, could just as well be regarded as having fully compositional meanings:

$\begin{array}{ll}\text { sky-blue } & \text { care-free } \\ \text { day-long } & \text { ring-leader } \\ \text { tear-gas } & \text { head-ache } \\ \text { short-sighted } & \text { moon-beam } \\ \text { color-fast } & \end{array}$

An additional problem with Allen's reanalysis of the examples in (39) concerns the form of the Permanent Lexicon. One of the consequences of the introduction of the notion of strecchable suffixation, is that the Permanent Lexicon contains a large number of morphologically conplex forms for which Allen's morphological theory offers no explanation. Allen needs two types of affixation rules within her morphological theory, viz. (i) affixation rules which are subject to the EOH, and (ii) affixation rules which attach stretchable suffixes to forms listed in the Perthanent Lexicon. However, Allen does not clarify the nature of stretchable suffixation as a process operating in the permanent Lexicon. Consequently, her theory offers only an arbitrarily restricted account of word formation in English.

The most fundamental problem with Allen's reanalysis of the apparent counterexamples to the $\mathrm{EOH}$, is the complete absence of arguments in 
support of the distinction between stretchable and non-stretchable suffixes. According to Allen (1978:239),

\footnotetext{
"stretchable suffixation is not a part of regular wordformation, but a marginal and idiosyncratic feature of a smal1 number of derivational suffixes."
}

Allen does not attempt to characterize the notion 'stretchable suffixation' in such a way that it becomes possible to predict whether or not a suffix $S$ will have the status of a stretchable suffix. Such an independent characterization would have contributed much to the plausibility of her theory. However, the fact that she finds it necessary to postulate a process which she herself regards as "marginal and idiosyncratic", casts serious doubts on the credibility of the EOH. If an independently motivated characterization of the notion 'stretchable suffix' were available, the distinction between "ordinary" and "stretchable" suffixes would have been more clear. Such a characterization could also have formed the basis for an explanation of the non-occurrence of "stretchable prefixes". In the absence of such a characterization, however, the notion 'stretchable suffixation' remains a marginal, ad hoc device, introduced solely for the purpose of saving the EOH from refulation.

\subsubsection{The suffix $-2 y$}

Selkirk (1978:21) also presents the following examples of compound adjectives to which $-2 y$ has been attached:

(44) $\quad[$ [praiseworthi $\left.]-\tau_{y}\right]$

$[$ [breathtaking $\left.]-z_{y}\right]$

Allen (1978:241-243) treats these examples separately, holding that they represent two distinct types.

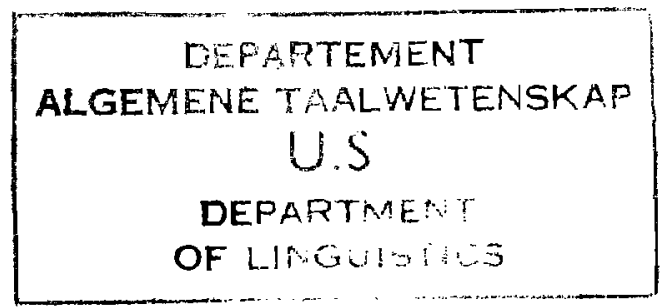




\subsubsection{The type praiseworthizy}

Allen (1978:242) argues that forms such as praiseworthily cannot be regarded as counterexamples to the EOH. According to her,

"... examples in -worthily cannot be construed as counterexamples to the Extended Ordering Hypothesis since -worthy is a Level II word-boundary suffix ... The evidence for this claim is that adjectives in -worthy can be prefixed by un-: untrustworthy, unseaworthy. True compound adjectives cannot be prefixed by un-: *uncollege-educated, *unocean-going. Therefore-worthy must be a Level II word-boundary suffix, not a constituent of a compound. The Level II word-boundary suffix -ness can also attach to -worthy adjectives, which is to be expected if -worthy is itself a Level II suffix: trustworthiness, seaworthiness. The attachment of adverb-forming -ly to adjectives in -worthy is consequently not problematic."

The reanalysis of -worthy as a Level II \#boundary suffix forms the basis of Allen's strategy to protect the EOH from refutation. She presents two arguments which can be reconstructed as follows:

(45) (a) Level II \# boundary affixes may attach to words derived by Level II affixation rules.

(b) Adjectives in -worthy may be (i) prefixed by the Level II \# boundary prefix un- and (ii) suffixed by the Level II \# boundary suffix -ness.

(c) Thus, worthy is a Level II \# boundary suffix and not a constituent of a compound.

(46) (a) Level II \# boundary affixes may attach to words derived by Level I I affixation rules.

(b) The suffixes -worthy and - $2 y$ are both Level II \#boundary suffixes.

(c) Thus, praiseworthily is not a compound derivative and consequently not a counterexample to the EOH. 
What Allen in fact does in the case of -worthy, is to argue that praiseworthity is not analyzable as a compound, praiseworthis, to which the suffix - ly has attached, but rather as a derived word with two suffixes, worthy and $-l y$.

Allen's reanalysis of praiseworthizy as a derivative is non-objectionable. Marchand (1969:356-357) does not regard adjectives formed by attaching worthy as compound adjectives. According to him, adjectives formed by -worthy Suffixation can be prefixed by un-, whereas compound adjectives cannot be prefixed at a11. Marchand regards -worthy as a so-called "semi-suffix". He (1969:356) considers "semi-suffixes" to be

"such elements as stand midway between full words and suffixes. Some of them are used only as second words of compounds, though their word character is still clearly. recognizable."

However, neither Allen, nor Marchand investigates the difference(s) between the word worthy and the suffix -worthy. Consider the two instances of worthy in the sentences (47)(a) and (b) respectively.

(47) (a) He is worthy of your trust/praise.

(b) He is tmustworthy/praiseworthy.

In $\S \S 4.3 .1$ and 4.3 .2 above, we considered Allen's attempts at distinguishing between two morphemes ful and two morphemes less. Recall that she (1978:234-236) draws a distinction between the \#boundary suffixes $-f u l_{1}$ and - less $_{1}$ and the morphemes $f_{u} z_{2}$ and $l_{e s s_{2}}$ which are Eree words. In both cases, she provides some evidence for the distinction. In the case of worthy, however, Allen makes no effort to point out the differences between the \#boundary suffix worthy and the word worthy, which is an unfortunate omission on her part. On the whole, however, the hypothesis that -worthy, in words such as praiseworthy, is a Level II \# boundary suffix, may be regarded as fairly non-ad hoc. Therefore, Allen is quite justified in claiming that the existence of words such as praiseworthy does not bear negatively on the EOH. 


\subsubsection{The type breathtakingly}

Although the attachment of adverb-forming - iy to adjectives in -worthy can be explained, there are a few cases in which - ly attaches to forms other than worthy. The following examples are presented by Allen (1978:242):

$$
\begin{aligned}
& \text { breathtakingly } \\
& \text { painstakingly } \\
& \text { level-headedly } \\
& \text { single-handedly } \\
& \text { whole-heartedly } \\
& \text { single-mindedly }
\end{aligned}
$$

Having discussed the potential counterexamples in (48), Allen (1978: 242-243) concludes that the few cases in which - ly attaches outside compounds "are not illustrative of a general morphological pattern". She argues as follows for this conclusion:

"... it seems to me that adverb-forming $-1 y$ is another case of a stretchable suffix. First of all, there are cases in which -ly attaches to phrasal units which are lexicalized, e.g.:

$$
\begin{aligned}
& \text { matter-of-factly } \\
& \text { stand-offish ly }[\text { sic }] \\
& \text { Mark Twainish ly }
\end{aligned}
$$

The few compounds to which - Iy may attach are also lexicalized to some extent (e.g. level-headed, single-handed, painstaking). It is quite clear that -ly does not attach to productive, compositional adjectives: "freedom-lovingly, "color-blindly, *bitter-sweetly, "life-givingly, "chicken-heartedly."

The notion 'stretchable suffix' again forms the basis of a strategy for protecting the EOH. from disconfirming evidence. This strategy consists in Allen's presenting two arguments that may be reconstructed as follows: 
(a) Stretchable suffixes

(i) attach to lexicalized phrascs and compounds listed in the permantent loxicon;

(ii) do not attach to compounds with compositional meanings which are formed by productive rules.

(b) The suffix $-l_{y}$

(i) attaches to lexicalized phrases and compounds listed in the Permanent Lexicon, e.g. matterof-factly, level-headediy;

(ii) does not attach to compounds with compositional meanings which are formed by productive rules, e.g. *freedom-tovingly.

(c) Thus, the suffix - ty is a stretchable suffix.

(50) (a) The suffix - $2 y$ is a stretchable suffix which attaches to items in the Permanent Lexicon.

(b) The EOH does not apply to morphological processes operating within the Permanent Lexicon.

(c) Thus, the existence of forms such as breathtakingly, in which - ly appears outside a compound, cannot be construed as a violation of the EOH.

The strategy employed by Allen to protect the EOH from potential disconfirmation by forms such as breathtakingly, is essentially the same as the strategy by means of which she attempted to get rid of potential counterevidence involving the appearance of the suffixes -ness, -ish and $-y$ outside compounds, as in (41) above. Allen (1978:242-243) acknowledges this when she remarks that

\footnotetext{
"... it seems that $-1 y$ requires the same kind of idiosyncratic statement necessary for the stretchable suffixes =ness, -ish and $-y$."
}

Allen herself (1978:243) notes that the data in support of the analysis 
of -ly as a stretchable suffix are not as clear as those presented in support of the analysis of the other three suffixes as stretchable suffixes. Consequently,

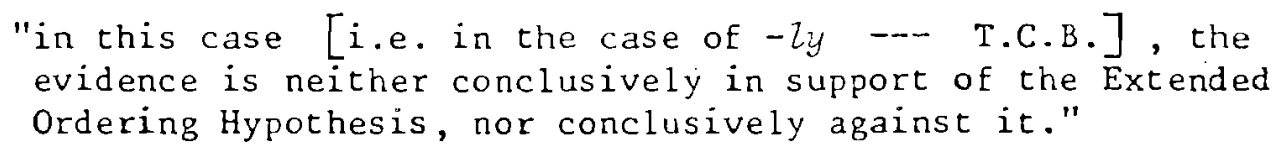

The mere fact that Allen does not regard the evidence derived from - ty adjectives as bearing positively on the merit of the EOH, reduces the power of her argumentation considerably. Moreover, the same objections that were raised in $\S 4.3 .3$ against the notion 'stretchable suffixation' apply in the case of - $l y$. These objections concern Allen's notion 'lexicalized', the form of the Permanent Lexicon, and the grounds for introducing the notion 'stretchable suffixation'.

\subsubsection{The suffix $-e d$}

The last class of potential counterexamples to the EOH noted by Selkirk and presented by Allen (1978:243, 245, 246), includes forms such as the following:

$$
\begin{aligned}
& \text { [shirt sleeve] d }{ }^{36)} \\
& {[\text { snow-suit }] \text { ed }} \\
& \text { [bowler-hat] ed } \\
& \text { [pig-head] ed } \\
& \text { [lion-heart] ed }
\end{aligned}
$$

According to Allen (1978:245), the adjective-forming \#boundary suffix -ed generally cannot attach to $\mathrm{N}-\mathrm{N}$ compounds.

$$
\begin{aligned}
& *[\text { beach-pebble }] \\
& *[\text { pencil-point }] \\
& \text { d] }
\end{aligned}
$$

In the case of shirt-sleeved, snow-suited, bowler-hatted, pig-headed, 
etc. -ed appears to attach to $\mathrm{N}-\mathrm{N}$ compounds. According to Allen (1978:245), the bracketings in (51) above are motivated by semantic considerations. She $(1978: 246)$ then argues, on the basis of morphological considerations, that the bracketing of these forms should be different. Thereby she attempts to deny the forms in (51) the status of true counterexamples to the EOH. In essence, she (1978:246-247) argues that

"... the -ed suffix attaches productively to nouns of certain semantic classes, and as an overgenerating suffix forms -ed adjectives such as the following.

$\begin{array}{lllll}\text { pebbled } & \text { pointed } & \text { treed } & \text { sided } & \text { flowered } \\ \text { moneyed } & \text { forested } & \text { crusted } & \text { sleeved } & \text { suited } \\ \text { hatted } & \text { booted } & \text { footed } & \text { headed } & \text { handed } \\ \text { fisted } & \text { bearded } & \text { forked } & \text { hooded } & \text { sleeved }\end{array}$

Theories of morphology which do not involve the notion overgeneration, .... are ... faced with a problem in explaining the occurrence of words which have no independent status as lexical items, and yet appear freely in compounds; for example sleeved, hearted ... appear in the compounds shirt-sleeved, lion-hearted ... A non-overgenerating theory can only deal with these cases by attaching the -ed suffix outside the compound, as does Selkirk ... The attachment of the -ed suffix to simple nouns is necessarily an overgenerating rule. This being so, all denominal -ed adjectives which appear in compounds, whether they occur as independent lexical items or not, will be available for direct adjunction with other lexical items to form compound adjectives.

Now, there is a rule of compound adjective formation which adjoins nouns and adjectives on the pattern of color-blind... e.g.

$$
\left[[\cdots]_{\mathrm{N}}[\cdots]_{\mathrm{A}}\right]_{\mathrm{A}}
$$

Any adjective, derived or underived, may participate as the second constituent in $\mathrm{N}$ - A adjective compounding. Consequently, all-ed adjectives ... may appear as the second constituent of $N$ - $\overline{A c o m p o u n d s . ~ I n ~ o t h e r ~ w o r d s, ~ a l l ~ c o m p o u n d ~ a d j e c t i v e s ~}$ containing the linear sequence $\mathrm{N}-\mathrm{N}$ - ed are analysable as

$$
\left[[\ldots]_{N}\left[[\ldots]_{N}-e d\right]_{A}\right]_{A}
$$

... Semantic considerations ... support the proposed analysis of $\mathrm{N}-\mathrm{N}$ - ed adjectival compounds."

The claim that $N-N-e d$ compound adjectives must be analyzed as $\underline{N}-A$ 
compounds, forms the basis of a strategy employed by Allen to protect the EOH from refutation. This strategy consists in Allen's presenting two arguments which may be reconstructed as follows:

(53) (a) The rule of Adjective Compounding adjoins nouns to adjectives: $\left[[\ldots]_{\mathrm{N}}[\ldots]_{\mathrm{A}}\right]_{\mathrm{A}}$.

(b) The overgenerating rule of -ed Suffixation generates adjectives of the form $\left[[\ldots]_{\mathrm{N}} \text {-ed }\right]_{\mathrm{A}}$.

(c) Thus, compound adjectives containing the linear sequence $\mathrm{N}-\mathrm{N}$ - ed can be analyzed as $\left[[\ldots]_{\mathrm{N}}\left[[\ldots]_{\mathrm{N}}-e d\right]_{\mathrm{A}}\right]_{\mathrm{A}}$.

(54) (a) According to the EOH, no affix may appear outside a compound.

(b) Compound adjectives containing the linear sequence $\mathbf{N}-\mathbf{N}-e d$, such as shirt-sleeved, are analyzed as $\left[[\cdots]_{\mathrm{N}}\left[[\ldots]_{\mathrm{N}}-e d\right]_{\mathrm{A}}\right]_{\mathrm{A}}$.

(c) Thus, forms such as shirt-sleeved do not constitute a violation of the EOH.

Allen (1978:251) presents additional evidence for her analysis of $\underline{N-N-e d}$ compound adjectives in the form of $A-N-e d$ compound adjectives such as the following:

$$
\begin{aligned}
& \text { hard-hearted } \\
& \text { heavy-handed } \\
& \text { bushy-tailed } \\
& \text { one-handed }
\end{aligned}
$$$$
\text { three-cornered }
$$

According to Allen (1978:252), an analysis of these compound adjectives as compound nouns with an external -ed suffix is impossible within her morphological theory. The reason for this is that there is no overgenerating rule of $A-N$ compound formation which produces forms such as the following: 
(56)

$$
\begin{aligned}
& \text { *hard-heart } \\
& \text { *héavy-hand } \\
& \text { *bushy-tail } \\
& \text { *óne-hand } \\
& \text { *thrée-corners }
\end{aligned}
$$

Consequently, there are no bases on which the -ed Suffixation rule can operate. Allen (1978:252) discusses the possibility that A - N compounds may not be formed by a regular process of word formation. Rather, they may arise in the lexicon as the result of a reanalysis of lexicalized pirases:

$$
\begin{aligned}
& \text { hard héart } \\
& \text { heavy hánd } \\
& \text { bushy táiz } \\
& \text { one hánd } \\
& \text { three córners }
\end{aligned}
$$

Such an analysis would imply that -ed attaches to phrases. Allen (1978: 253) notes that an analysis in which -ed attaches to phrases is unacceptable, since it makes empirically false predictions. For example, on such an analysis, it should be possible for -ed to attach to phrases which are properly specified for number agreement, e.g. two hands, four comers, five feet. Allen (1978:253) shows that this is impossible: whenever -ed appears as a suffix, there is no marker of plurality on the noun:

$$
\begin{aligned}
& \text { two-handed } \\
& \text { four-comered } \\
& \text { five-footed }
\end{aligned}
$$

$$
\begin{aligned}
& \text { *wo-handsed } \\
& \text { *four-comersed } \\
& \text { *five-feeted }
\end{aligned}
$$

According to Allen (1978:253),

"The absence of the plural inflection in these examples is predictable only when $\mathrm{A}-\mathrm{N}$-ed compound adjectives are analysed with the -ed suffix inside the compound; i.e. 
(344)

$$
\left[[\cdots]_{A}\left[[\cdots]_{N} \text { ed }\right]_{A}\right]_{\Lambda}
$$

The regularly derived, overgenerated -ed adjectives hearted, handed, Footed, etc. are compounded with a modifying adjective (two, many, four, etc.) in the derivational morphology at a point where questions of plurality specification by gramatical inflection are not relevant."

Thus, Allen analyzes all compound adjectives containing the linear sequence $A-N$ - ed as $A-A$ adjectival compounds with the following internal morphological structure:

$$
\left[[\cdots]_{\mathrm{A}}\left[[\ldots]_{\mathrm{N}}-e d\right]_{\mathrm{A}}\right]_{\mathrm{A}}
$$

According to Allen (1978:254), compound adjectives such as those in (60), with the internal morphological structure of (59), constitute

"a subset of a more general adjective compounding process in which two non-compound adjectives, simple or derived, are adjoined." 38)

(60)

$$
\begin{aligned}
& \text { grey-green } \\
& \text { icy-cold } \\
& \text { easy-going } \\
& \text { bitter-sweet }
\end{aligned}
$$

On this analysis no reference is made to the internal morphological structure of the constituent adjectives.

Allen's reanalysis of the counterexamples in -ed is not without problems. Particularly questionable are aspects of her discussion of the attachment of -ed to phrases. According to her (1978:253), the claim that -ed may attach to compounds would imply that -ed can attach to phrases like two hands or four comers as well. However, this is not possible. No inflectional affixes may appear inside -ed: 
Allen's argument is valid only on the assumption that word formition rules apply to surface structure phrases. It is possible to argue that forms such as two-handed and foup-comered are formed on the basis of deep structure phrases. A general principle will then prevent the deep structure features representing number, etc. from being realized in derived words. On this analysis, it will be impossible for the suffix -ed to attach to a form such as two-hands or fourcomers. 39)

Allen (1978:249, 255) attempts to provide semantic considerations as supporting evidence for her analyses of $\mathrm{N}-\mathrm{A}$ and $\mathrm{A}-\mathrm{A}$ compounds. According to her (1978:249), the analysis [beach-pebble]d falsely predicts that beach-pebbled means "having bcach-pebbles". By contrast, the analysis [beach] [pebbled] correctly predicts the meaning "pebbled like a beach". Likewise, she (1978:255) argues that the semantic interpretation of compounds such as tight-fisted is "fisted modified by tight".

Botha (1980:152 n.9) notes that it is of some importance to Allen that beach-pebbled should be analyzed as in (62) (a) and not as in (62) (b).

\section{(a) [beach $][$ pebbled] \\ (b) $\quad[$ beach-pebble $] d$}

The analysis (62)(b) contradicts the ordering claim of the EOH that no affix can attach to a compound. In this case, the analysis in (62) (a) forms the basis of the correct semantic interpretation of the compound, viz. "pebbled like a beach". However, Botha (1980:152 ה.9) observes that morphological representations of the type (62)(a) make incorrect predictions about the meanings of compounds such as shirt-s eeved, snow-suited and souler-hatted: ${ }^{40}$
(a) $[$ shirt $][$ sleeved $]$
(b) $[$ snow $][$ suited $]$
(c) [bouler $][$ hatted] 
The form shirt-sleeved does not have the meaning "sleeved like a shirt", which is the meaning predicted by the analysis (63) (a). Likewise, snow-suited does not mean "suited like snow", and bowler-hatted does not mean "hatted like a bowler". These compounds rather have the meanings predicted by the analysis (62)(b), viz. "characterized by the presence of shirt-sleeves", "characterized by the presence of (a) bowler-hat (s)", etc. Alien makes no attempt to account for the former incorrect predictions of the EOH.

The remarks regarding the semantic interpretation of compound adjectives such as hard-hearted and tight-fisted are not entirely convincing either. Allen's claim that the compositional meaning of compound adjectives is essentially that of "modifier-modified" is so.vague that it can contribute little to the specification of the meaning of the compound.

It is possible to assign meanings such as "having a hard heart", "having a tight fist", etc. to the forms hard-hearted and tight-fisted. However, these meanings cannot be derived from the analyses [hard] [hearted] and [tight] [fisted], which Allen (1978:255) proposes. We have to conclude that the semantic interpretation "modifier-modified" which Allen assigns to compound adjectives, is too vague to contribute to the credibility of her analysis. In sum, Allen does not succeed in arguing convincingly against the potential -ed counterexampies to the EOH. The hypothesis that the rule of Adjective Compounding adjoins nouns to adjectives, irrespective of the internal morphological structure of the adjectives, should be regarded as ad hoc. The sole function of this hypothesis seems to be that of protecting the EOH from refutation.

This concludes the discussion of Allen's treatment of potential counterexamples to the EOH involving the occurrence of suffixes outside compounds. The following points emerged from the discussion:

(a) The form - ful which appears outside compounds is not the suffix -ful, but the word fuzt. Thus, forms in which -fuz attaches to a compound do not violate the EOH.

(b) The form -wortiny which appears in complex words such as praiseworthy, is a suffix. Thus, the attachment of -ly to words containing -worthy does not violate the $\mathrm{EOH}$. 
(c) The reanalyses of the forms in which - less, -ness, -ish, $-y$, $-2 y$ and -ed attach to compounds are all unacceptable. Thus, these forms must be regarded as real counterexamples to the EOH.

The acceptability of the various strategies employed by Allen to protect the EOH from refutation will be discussed in $\$ 6$.

\section{.5 English primary compounds as bases of affixation rules}

We will now briefly consider the views of other linguists on the appearance of affixes outside compounds in English. Jespersen (1946:336) notes that "occasionally -ism words may be derived from ... compounds". Sone of his examples are:

(64)

$$
\begin{aligned}
& \text { old-maidism } \\
& \text { public-schoolism } \\
& \text { spread-eagleism }
\end{aligned}
$$

\begin{tabular}{|c|c|}
\hline$(65)$ & $\begin{array}{l}\text { old-maidish } \\
\text { schoolginish }\end{array}$ \\
\hline & blackguardism \\
\hline & brockheadism \\
\hline & Zandzondism ${ }^{42)}$ \\
\hline & At tomey-generalship \\
\hline & $\begin{array}{l}\text { head-misiress-ship } \\
\text { postmastership } \\
\text { newspaperdom } 4 \text { 4) }\end{array}$ \\
\hline
\end{tabular}

The following examples are also presented by Jespersen (1946):

\footnotetext{
In his discussion of derivatives formed from adjunct + substantive sequences, Jespersen (1946:235) explicitly states that derivatives can also be formed on the basis of
} 


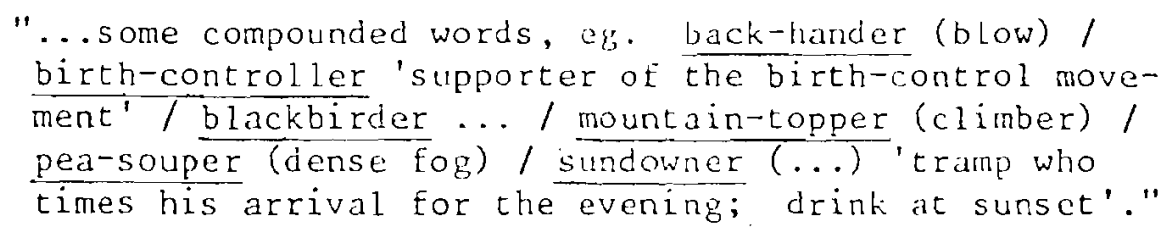

Marchand (1969:50, 265, 280) also cites some examples which can be regarded as cases where affixes attach to compounds, although he does not present them as such.

\begin{tabular}{|c|c|c|c|c|}
\hline \multirow{9}{*}{\multicolumn{2}{|c|}{$(66)$}} & colorblindness & (b) & weekender \\
\hline & & selfconsciousness & & carpetbagger \\
\hline & & colorfastness & & bobbysoxer \\
\hline & & thread-bareness & & $n i g h t-l i f e r$ \\
\hline & & tongue-tiedness & & pigtaizer \\
\hline & & cockfighting & & first-nighter \\
\hline & & palefaced & & underworzder \\
\hline & & hunchbacked & & Scotzand-Yarder \\
\hline & & knock-kneed 45) & & backhander \\
\hline
\end{tabular}

Adams (1973:34) comments on forms such as first-nighter, which she regards as "derivational compounds". According to her,

\footnotetext{
"Derivational compounds which are not parasynthetic are exemplified by first-nighter, broken-hearted, made up of the compound stems first night, broken heart and the suffixes -er, -ed." 46 )
}

Another proponent of the view that affixes can appear outside compounds, is Levi (1977). According to her (1977:326-327), the very fact that derivational affixes attach to both nouns and complex nominals, constitutes evidence for her claim that complex nominals are dominated by the node label $\mathrm{N}^{47}$ )

The following data presented by Levi (1977:328) are of interest to us: 


\author{
intellectuat histonian \\ histowent linglist \\ quantam mechanician \\ statistical mechaniaian \\ classieat mechanician
}

According to Levi (1977:328), intelzectual histowan means neither "a historian who is intellectual", nor "a historian dealing with the intellect". Rather, it means "one who does [what is known as] intellectual history". Similarly, a histomical linguist is not a linguist dealing with history, but one who does historical linguistics. A quantum mechanician is a physicist who specializes in quantum mechanics, a statisticat mechaniaian is a physicist who specializes in statistical mechanics and a classical mechanician is a physicist who specializes in classical mechanics. In order to derive the correct meanings for these complex nominals, Levi (1977:328) assigns them the following internal bracketings:

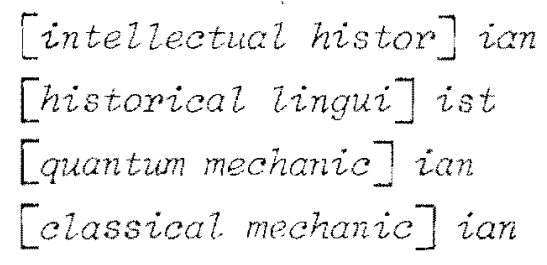

Levi's (1977:328) conclusion is that

"the phrase quantum mechanician in $7(\mathrm{c})$ [i.e. with the inter-
nal bracketing as in (68) above - T.C.B.] nust be derived
not by combining the nonexistent noun mechanician with the
noum quantum, but rather by combining the full CN [i.e.
complex nominal. -- T.C. B.] quantum mechanician with the
appropriate agentive suffix." 48 )

Consequently,

"it is these [i.e. the cases in (68) above --- T.C.B.] which force us to conclude that these suffixes may be attached to the $\mathrm{CN}$ [i.e. 'complex nominal' .... T.C.B.] as a whole rather than just to the head noun." 49) 
Levi's claim that complex nominals are in fact nouns is not relevant here. What is inportant, though, is the type of evidence which she furnishes in support of her claim. 50)

As was shown in previous paragraphs, Selkirk (1978:21) also presents a number of examples which, according to her, must be analyzed as consisting of a compound stem and a neutral affix. She (1978:17) identifies four fundamental properties which distinguish neutral affixes from non-neutral affixes in English. The property relevant to the present discussion is the one which she formulates as follows:

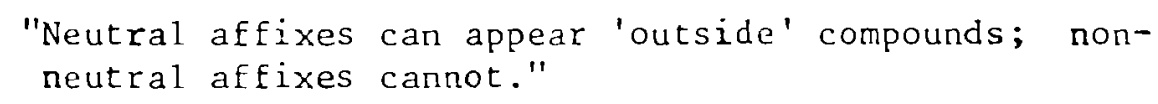

Examples of the data which Selkirk (1978:21) presents as evidence in support of the claim (69) were discussed above. Some of the forms are repeated in (70).

$$
\begin{aligned}
& {[\text { [shirt sleev }] \text {-ed] }} \\
& [\text { [home sick }] \text {-ness }] \\
& {[[\text { tear gas }]-y]} \\
& [\text { un-[God fearing }]] \\
& {[\text { re- }[\text { air-condition }]]^{51)}}
\end{aligned}
$$

(Selkirk 1981:270-271) also deals with the appearance of affixes outside compounds. In this study she claims that the suffix -hood which usually attaches to single nouns as in neighboriood, may attach to compound nouns as well. She presents the following examples:

$$
\begin{aligned}
& \text { At the beginning, fiften wear old Nancy was a confimed } \\
& \left\{\begin{array}{l}
\text { pick pocket } \\
\text { run away } \\
\text { movie buff }
\end{array}\right\} \text { but the period of her }\left\{\begin{array}{l}
\text { pick pocket } \\
\text { ritn away } \\
\text { movie buff }
\end{array}\right\}-\text { hood } \\
& \text { turned out to be of relative? siont duration. }
\end{aligned}
$$

According to Selkirk (1981:270), the example min away-hood unmistakably shows that the suffix -hood must attach to the compound as a whole and 
not to the righthand constituent ot the compound. Given the fact that "a preposition does not accept affixes, nor docs hood accept prepositions", no other conclusion is possible. Selkirk (1981:271) points out that this conclusion has serious consequences for morphological theories which separate compounding and effixation processes into discrete subsystems of the grammar. A level-ordered morphological theory, as proposed by siegei (1974) and by Ailen (1978), requires all affjxation rules to operate before all compound rules. Hence, all affixes, both derivational and inflectional, must be contained within compounds and cannot appear outside them. ${ }^{52}$ )

The preceding discussion has revealed that various linguists adopt the position that affixes may appear outside compounds in English. Allen's (1978) attempted reanalysis of the examples presented by Selkirk (1978:21) does not remove the threat to the EOH. Other examples, such as those presented by Jespersen (1946), Marchand (1969), Adams (1973), Levi (1977) and Selkirk (1981), remain to be accounted for.

\section{Conclusion}

In this chapter $I$ have isolated the major shortcomings of Allen's defence of the EOH. It was shown that, with two exceptions, all the protective devices which she employs in denying certain counterexamples the status of actual counterexamples to the EOH, are objectiorable. In (72), a brief sumnary of these protective devices is presented. 
(72)

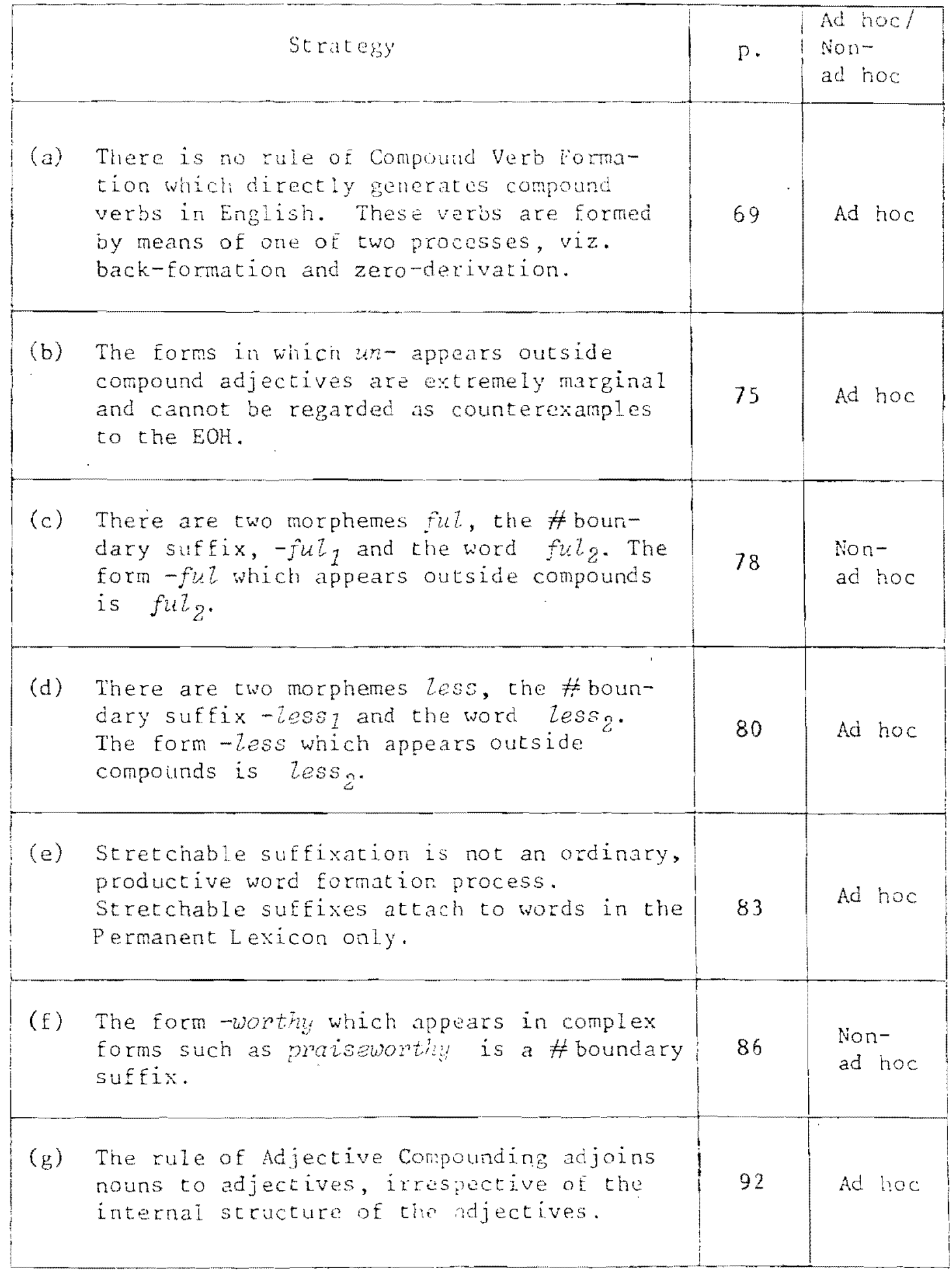

Only two of the seven strategies which Allon enploys in defence of the EOH have been Found to be non-ad hoc. A question that has not yet been raised is whether protection as such is an objectionable way of reacting co criticism brought against a hypothesis. According to Botha (1981a: 
417), the protection of a criticized hypothesis need not necessarily be objectionable. According to him (1981:4:43-417), protection of a hypothes is by means of ad hoc auxiliary hypotheses is objectionable, whereas protection of a hypothesis by means of non-ad hoc auxiliary hypothesis is not. An auxiliary bypothesis is ad hoc ie (i) its sole Function is to protect another hypothes is from refutation and (ii) it has no independent test implications, i.e. it is in principle irrefutable. 53) Except for (c) and (f), the protective devices in (72) above have all been shown to be ad hoc. Their sole purpose is to render potential counterexamples compatiole with the EOH. The protective devices (72)(a), (b), (d), (e) and (g) should therefore be regarded as objectionable and, hence, unacceptable measures of protection. Consequently, we have to conclude that quite a number of real counterexamples to the EOH remain unaccounted for. Note that the fact that Allen chooses protection as a means of reacting to criticism brought against the $\mathrm{EOH}$ is not objectionable in itself. The problems which we have noted in connection with the devices (72) (a), (b), (d), (e) and (g) arise from the content of Allen's arguments in each case.

It was noted in 82 that Allen (1978) is not very explicit about the status of the EOH. It is therefore difficult to make judgments about the success of this hypothesis. Suppose, for argument's sake, that the EOH was conceived as a rule-independent, but language-specific principle of English morphology. Then the fact that a considerable number of English forms remain unaccounted for by the EOH, bears negatively on this hypothesis. It must be concluded, therefore, that the EOH does not entirely succeed as a principle for explaining the formation of compounds and derivatives in English. It follows then, that Allen's (1978:196) claim that it is "a general ordering principle of morphology which drastically limits the number of possible combinations of prefixes and suffixes", is highly questionable. 
NOTES

*This paper is based on part of an M.A. thesis, which was presented at the University of Stellenbosch in 1982. It was written under the supervision of Prof. R.P. Botha.

1. Cf. T.C. Botha 1982 for a detailed discussion of the consequences of the EOH.

2. Allen (1978) uses the term "level" instead of "class" in order to capture the fact that the morphology is partitioned into blocks of rules, each block having different morphological characteristics. In her discussion of the $\mathrm{EOH}$, Allen does not give much attention to the second part of the EOH, viz. that "the assignment of external word-boundaries to lexical items is ordered after affixation rules but before compounding" (1978:83). Apart from one paragraph in which she (1978:126-128) comments on the assignment of external word-boundaries, Allen is mostly concerned with the appearance of affixes outside compounds. In the present study, no attention will be given to the assignment of external word-boundaries.

3. Note that Allen (1978) uses the expression "Extended Ordering Hypothesis" in an ambiguous way. She uses the expression "the EOH" not only to denote an "extension" of the Ordering Hypothesis, but also to denote a hypothes is which in fact includes the ordering Hypothesis. The ambiguity arises from Allen's use of the term "extended". Cf. T.C. Botha 1982:2-4 for a more detailed discussion of Allen's ambiguous use of the expression "the EOH". I will assume that the $\mathrm{EOH}$ expresses only one claim, viz. that the Level III rules, including the compounding rules, follow all Level $I$ and Level II affixation rules.

4. In all the quotations the emphasis is mine. 
5. The emphasis is mine.

6. For a more detailed discussion of Allen's Overgenerating Morphology, cf. Allen 1978:\$4.2.2.

7. According to Allen (1978:196), the interaction of word formation rules can also be blocked by adopting rule-specific conditions. Such conditions include (i) the condition which limits un- Prefixation to adjectives and (ii) the condition which limits suffixation by verb forming -en to monosyllabic adjectives.

8. Allen (1978:213,231, etc.) repeatedly refers to "Level III formed compounds" or "Level III derived compounds". This implies that compounds may also be formed on levels of word formation other than Level III. However, this is not implied by Allen's EOH. In order to avoid this ambiguity, I will refer to "compounds which are formed at Level III", or just "compounds".

9. Cf. Allen 1978:213-214 for further discussion of the interaction between an Overgenerating Morphology and the EOH.

10. This prediction will be discussed in detail in $\$ 4$.

11. Allen (1978:216) refers to rules that apply in the environment of a word-boundary as "\# rules". The rules of R-syllabification, G-drop and I-tensing would be \# rules, for example.

12. (Selkirk 1978) is an unpublished manuscript which represents a part of (Selkirk in preparation). Selkirk has since changed some of the views expressed in (Selkirk 1978). Allen's (1978) references to (Selkirk in preparation) are in fact references to (Selkirk 1978). Thus, although selkirk has changed some of her views, Allen's remarks will be judged against the background of (Selkirk 1978).

13. Selkirk (1978:23-24) presents evidence from two phonological processes in support of this conclusion, viz. from G-drop and from $R-$ syl labification. 
14. According to Selkirk (1978:11), the stem is "a structural unit in and of itself". Compounds, for example, would be regarded as being composed of stems. Neutral affixes are adjuncts to stems. By contrast, non-neutral affixes are adjuncts to roots. According to her (1978:14-15), a stem immediately and exhaustively dominates a root.

15. Selkirk has recently changed her views about the nature of the constituents of compounds. In (Selkirk 1981:271), compounds are regarded as being composed of words, and not of stems.

16. According to Allen (1978:22), "the suffixes ... -iike, ... -iy, ... - y have all been generally accepted as associated in some way with a word-boundary, the major evidence being that these suffixes affect neither the stress nor the segmental composition of the words to which they attach".

17. Recall that Selkirk (1978) distinguishes between neutral (\# boundary) and non-neutral ( + boundary) affixes which attach to stems and roots respectively. Within her theory, there is nothing which prevents neutral affixes from attaching to compounds.

18. Cf. Botha 1978:5-6 for a discussion of apparent/potential counterexamples and the difference between apparent and actual/real counterexamples.

19. The seven ways of reacting to criticism which Botha (1981a:408-409) lists, are (i) indifference, (ii) reasoned apathy, (iii) countercriticism, (iv) protection, (v) modification, (vi) replacement and (vii) revolution. One respect in which the various ways of reacting differ from one another, concerns the question of how drastic an effect each type of reaction has.

20. Cf. Botha 1981a:414-417 for a discussion of ad hoc and non-ad hoc auxiliary hypotheses.

21. Cf. (3) in $\$ 1$ for an explication of the ordering claims of Allen's morphological theory. 
22. Cf. Selkirk 1978:21 for these examples. The bracketing in the presentation of the words in (21) and (23) is that of Selkirk.

23. Cf. Allen $1978: 224,225$ for these examples.

24. In a note, Allen (1978:289) briefly considers the problem of an adequate description of the nature of the interaction of prefixation with compounds formed by back-formation. This note, note 19, is omitted from the quotation given here.

25. The rule of compound verb formation adjoins verbs and nouns to form compound verbs.

26. Exactly how prefixation applies in these cases is not clear. In note 19 of Chapter 4, Allen (1978:289) rejects the possibility of an account similar to the one proposed for stretchable suffixes. According to her, the correct account will possibly be that items in the Permanent Lexicon are subject to boundary weakening, which will permit external prefixation by Level II \# boundary prefixes. CE. Allen 1978:236ff. and $\$_{4.3 .3}$ of this study for a discussion of the notion "stretchable suffixation".

27. According to the Webster's Third International Dictionary (1961: 46), to air-condition means "to equip with an apparatus for washing, humidifying, de-humidifying and controlling the temperature of air". The verb to condition on the other hand (1961:473), has the meaning "to put into the proper or desired condition".

28. I will refer to the Websters's Third International Dictionary as Webster's for short.

29. Marchand (1969) uses the term "back-derivation" instead of "backformation". However, he (1969:3) apparently regards the two terms as synonyms, as the term "back-formation" appears in parentheses after "back-derivation".

30. Allen (1978:236) presents the following evidence in support of the 
hypothesis that $-f u \tau_{1}$ does not attach to compounds:

\begin{tabular}{|c|c|}
\hline worshipful & $*[s u n-w o n s h i p]$ fil \\
\hline carefuz & $*[\operatorname{chi} i d-c a n e]$ \\
\hline restful & $*[$ becl-rest $] f$ \\
\hline zowfuz & $*[j u n g l e-l o w]$ \\
\hline healthfui & $*[i n f a n t-h e a l$ \\
\hline masterfuz & $\because[$ house-mast \\
\hline thoughtful & ream-thor \\
\hline beautifuz & $*[a n i m a \tau-b e a$ \\
\hline
\end{tabular}

31. Cf. also Marchand 1969:291-292 for this distinction.

32. Cf. Nida 1946:89 n. 21 for this note.

33. Cf. Nida 1946:82 for this statement.

34. Note, incidentally, that Marchand (1969:324, 325) does not draw a distinction between two instances of less, as he does in the case of ful. He mentions only the less found in words such as careless, endless, headless, etc. According to him (1969:324), "combinations with -less are suffixal words. The suffix is primarily used with substantival bases, conveying the privative meaning 'without, free from _.". He also notes that the suffix-less is pronounced [1is] or [12s]. The possibility that it can be pronounced [1ss], is not mentioned.

35. According to Allen (1978:237), the only possible bracketing for these cases is one in which the suffix appears outside the phrase. The suffix cannot be attached to the final conjunct, e.g.* [black] and $[\text { bueness }]_{N}$, since constituents of different syntactic categories cannot be conjoined.

36. This example, together with the form hard-hearted, is presented by Selkirk (1978:21). The type of morphologically complex word to which hard-hearted belongs, will be discussed later.

37. Selkirk (1978:21) analyzes hard-hearted as [ [hara heart] ed]. 
38. Note that there is a problem with Allen's formulation. A particular type of compound cannot form a "subset" of a "more general adjective compounding process". Rather, a given type of compound can form a subset of the products of a more general adjective compounding process.

39. An exampie of such a general principle is the Morphological Island Constraint proposed by Botha (1981b:46):

"The individual constituents of the complex words formed by means of WFRs lose the ability to interact with inflectional, derivational and syntactic processes."

The Morphological Island Constraint will not be discussed in any more detail. Cf. Botha 1981b:45-55 and Savini in preparation for a more detailed discussion of this constraint.

40. Recall that Allen (1978:246-248) treats these examples as N-A compounds with the morphological structure $\left[[\ldots]_{\mathrm{N}}\left[[\ldots]_{\mathrm{N}} \text {-ed }\right]_{\mathrm{A}}\right]_{\mathrm{A}}$.

41. Cf. Jespersen 1946:325 for the last two examples.

42. Cf. Jespersen 1946:336 for the last three examples.

43. Cf: Jespersen 1946:460 for the last three examples.

44. Cf. Jespersen 1946:462 for this example.

45. Note that Alien would not regard the examples in (66) (a) as problematic for the EOH. Recall that she regards-ness as a "stretchable suffix", and that she analyzes complex adjectives ending in -ed as compounds with an -ed adjective as second constituent. However, in $\$ \$ 4.3 .3$ and 4.3 .4 it was argued that Allen's analyses cannot be accepted.

46. According to Adams (1973:33), a complex word such as unadventurousness may be "broken down" in the following way: unadventurous and -ness; un- and adventurous; adventure and-ous. Formations 
which cannot be "broken down" like this, are called "parasynthetic". The form intramscular, according to her (1973:33-34), is parasynthetic. If the suffix is subtracted, there is no word intramuscle. She notes that "we may here think of the prefix and the suffix as being added 'simultaneously' to the stem". She regards mitz shake as a parasynthetic compound, since the noun shake is not used in this sense outside the compounä.

47. Levi (1977:325; 1978:1) uses the one term "complex nominal" to denote the following types of nominals:

(i) nonpredicating/nominal adjectives, e.g. planetary core;

(ii) compound nouns/nominal compounds, e.g. apple core;

(iii) nominalizations, e.g. urban planning.

She $(1977: 325$; 1978:6) claims that all complex nominals are transformationally derived by means of two syntactic processes: predicate deletion and predicate nominalization.

48. Levi (1977:328) mistakenly notes that "the fu1l CN quantum mechanician" combines with the agentive suffix. This should presumably read "the ful1 CN quantum mechanic" combines with the agentive suffix, -ian.

49. The emphas is is Levi's.

50. Note that the examples in (68) constitute potential counterexamples to Allen's EOH. Allen does not consider a reanalysis of potential counterexamples to the EOH involving the agentive suffixes -ian and -ist.

51. The bracketing in (70) is that of Selkirk (1978:21).

52. Selkirk (1981:270-271) presents the evidence in (69) to support her argument that the category type involved in the formation of native compounds is that of word. According to her, the notion of 'category level' is important in describing the distribution of derivational affixes in English. For every affix, the level of the category to 
which it adjoins nust be specified. Because derivational afrixes may attach to either compound nouns or single nouns within her theory, these structures are of the same level. Therefore, the category type word is the one involved in compounding.

53. Cf. also Sinclair 1977:26 and Botha 1978:19 for a discussion of objectionable and non-objectionable protection. 


\section{REFERENCES}

Adams, $V$.

1973

An introduction to modern English word formation. . London: Longman.

Allen, M.R.

1978 Morphological investigations. Ph.D. Dissertation, University of Connecticut.

Aronoff, M.

1976

Word formation in generative grammar. ( Linguistic Inquiry Monograph One). Cambridge, Mass.: MIT Pross.

Botha, R.P.

1978 "Protecting general-1inguistic hypothesis from refutation", Stellenbosch papers in Linguistics $1: 1-38$.

1981a The conduct of linguistic inquiry. A systematic introduction to the methodology of generative gramar. The Hague, Paris, New York: Mouton.

$1981 \mathrm{~b}$ "A Base Rule Theory of Afrikaans synthetic compounding", in Moortgat et al. (eds.) $1981: 1-77$.

Botha, T.C.

1982 Primary compounds as bases of affixation rules in Afrikaans. M.A. Thesis, University of Stellenbosch.

Jackendoff, R.S.

1975 "Morphological and semantic regularities in the lexicon". Language $51: 639-671$.

Jespersen, 0 .

1946

A modern English granmar. London: George Allen \& Unwin Lta.; Copenhagen: Ejnar Munksguard. 
Levi, J.

1977

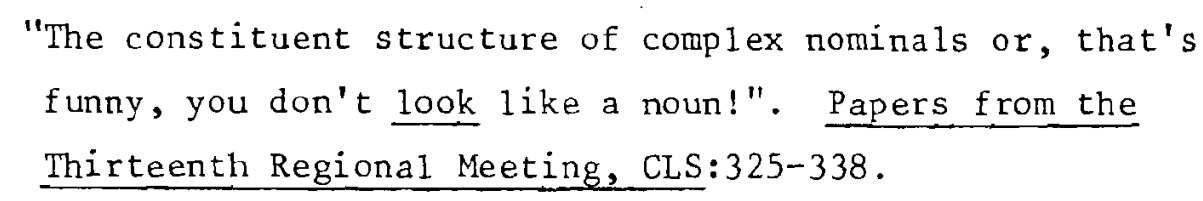

1978

The syntax and semantics of complex nominals. New York: Academic Press.

Marchand, $\mathrm{H}$.

1969

The categories and types of present-day EngIish wordformation. Second Edition. München: Beck.

Nida, E.A.

1946 Morphology: the descriptive analysis of words. Ann Arbor, Michigan: University of Michigan Press.

Selkirk, E.O.

1978 Untitled. Unpublished Ms., University of Massachusetts at Amherst.

1981

"English compounding and the theory of word structure", in Moortgat et al. (eds.) 1981:229-277.

in prepa- Phonology and syntax. The relation between sound and strucration ture. Cambridge, Mass.: MIT Press.

Siegel, D.

1974 Topics in English morphology. Ph. Dissertation, MIT.

Sinclair, M.

The refutability of Emonds's structure-preserving constraint. M.A. Thesis, University of Stellenbosch.

\section{DICTIONARIES}

Webster's Third New International Dictionary. 1961 (London; Springfield, Mass .) 